Disponível em

http://www.anpad.org.br/rac

RAC, Rio de Janeiro, v. 17, n. 3, art. 6, pp. 368-396, Maio/Jun. 2013

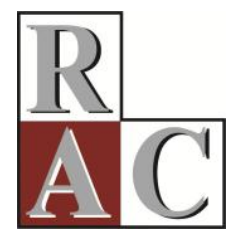

\title{
Sustentabilidade Ambiental: uma Meta-análise da Produção Brasileira em Periódicos de Administração
}

\section{Environmental Sustainability: a Meta-Analysis of Production in Brazilian Management Journals}

Maria Tereza Saraiva de Souza E-mail: mariaterezasaraivas@gmail.com Universidade Nove de Julho - PMDA/UNINOVE Alameda Ministro Rocha Azevedo, 644, apto. 43, Jardim Paulista, São Paulo, SP, 01410-000, Brasil.

Henrique César Melo Ribeiro E-mail: hcmribeirorac@gmail.com Universidade Nove de Julho - PMDA/UNINOVE Av. Rio Branco, 1658, São Paulo, SP, 06012-001, Brasil. 


\title{
Resumo
}

O objetivo deste estudo é investigar o perfil das pesquisas e a evolução do tema sustentabilidade ambiental nos artigos publicados em periódicos nacionais Qualis de Administração de A1 a B2, no período de 1992 a 2011. Trata-se de um estudo de análise bibliométrica para examinar a produção científica sobre o tema e nortear rumos e estratégias de futuras pesquisas. Os resultados mostraram que há alguns indícios que favorecem a qualidade e a consolidação da pesquisa em sustentabilidade ambiental no Brasil: a tendência de crescimento do número de artigos, mesmo que ainda concentrada em poucas revistas; a pluralidade de subtemas que surgiu principalmente nos últimos anos; o crescimento de estudos feitos por grupos de pesquisadores ao invés de iniciativas individuais; e o crescimento de estudos quantitativos que, a partir de 2007, foi maior que as pesquisas qualitativas, e a pluralidade de abordagens metodológicas. No entanto, ainda, são poucos os autores nacionais com histórico de pesquisa relevante e, nas referências, há citações internacionais e de autores nacionais que se destacam entre os mais citados e os que mais publicam.

Palavras-chave: bibliometria; ensino e pesquisa em administração; sustentabilidade ambiental.

\begin{abstract}
The objective of this study is to investigate the profile of research and development of the environmental sustainability theme in articles published in Brazilian management journals ranked A1 to B2 by Qualis from 1992 to 2011. It makes a bibliometric analysis of the scientific literature on the topic in order to offer direction and strategies for future research. The results showed that there is some evidence of increased research quality and force in Brazilian environmental sustainability studies: a growth trend in the number of articles, even if concentrated in a few magazines; a plurality of emerging sub-themes, especially in recent years; increased studies undertaken by research groups rather than individual initiatives; and a balanced distribution between quantitative and qualitative articles in recent years. On the other hand, there are few authors with a history of relevant research, and a limited number of international and national authors who stand out as the most cited and published.
\end{abstract}

Key words: bibliometrics; management teaching and research; environmental sustainability. 


\section{Introdução}

No Brasil, houve demora das empresas nacionais em internalizarem o conceito de desenvolvimento sustentável (Teixeira \& Bessa, 2009). As pesquisas sobre o desenvolvimento sustentável foram impulsionadas, no Brasil, somente na década de 1990, em decorrência da evolução da discussão e preocupação com a preservação do meio ambiente e com as condições sociais e econômicas da sociedade. Mesmo com os avanços que o tema sustentabilidade vem alcançando, há uma pluralidade de termos utilizados para evidenciá-lo, ou até mesmo das ações necessárias para alcançá-lo (Laruccia, 2012; Lyra, Gomes, \& Jacovine, 2009).

O clássico e mais citado documento da Comissão Mundial sobre Meio Ambiente e Desenvolvimento (CMMAD, 1988, p. 46) define o conceito de desenvolvimento sustentável com o seguinte enunciado: "é aquele que atende às necessidades do presente sem comprometer as gerações futuras a atenderem as suas próprias necessidades". As análises e recomendações da CMMAD (1988) e da Agenda 21 (Conferência das Nações Unidas sobre Meio Ambiente e Desenvolvimento [CNUMAD], 1996), outro importante documento, resultante da Rio 92, estão centradas nas dimensões ambientais, econômicas e sociais. Embora alguns autores importantes, como Sachs (1993), reconheçam outras dimensões da sustentabilidade, como a espacial e a cultural.

Para a Comissão (CMMAD, 1988), o termo desenvolvimento sustentável contém dois conceitos-chave: o conceito de necessidades básicas dos pobres de todo o mundo, que devem ser atendidas como prioridade, e o conceito de limitação dos recursos naturais, que pode impedir as gerações presentes e futuras de atenderem as suas necessidades. Esses dois conceitos, somados ao conceito de desenvolvimento econômico, convergem para o desenvolvimento sustentável, que busca o fim da pobreza, a redução da poluição ambiental e o desperdício no uso de recursos.

A partir dessas obras e das Conferências Mundiais sobre Meio Ambiente e Desenvolvimento, o termo desenvolvimento sustentável ficou consolidado e atrelado às dimensões ambiental, social e econômica, sem hierarquia e sobreposições entre essas três vertentes da sustentabilidade. Diversas áreas incorporaram os princípios do desenvolvimento sustentável, que, até então, eram propostas alternativas ao desenvolvimento econômico, criando novos campos do conhecimento como: agricultura sustentável, turismo sustentável, sustentabilidade empresarial, etc. Nas organizações, esses temas ainda se subdividem em operações sustentáveis, finanças sustentáveis e outros. A rigor, a gestão sustentável nas empresas e as pesquisas na área de sustentabilidade devem abarcar as três dimensões para justificar o uso do termo sustentável. No entanto, para cada uma das três dimensões da sustentabilidade, há uma definição específica. O recorte neste estudo foi a sustentabilidade ambiental, tomando como referência os conceitos definidos pela CMMAD (1988), Agenda 21 (CNUMAD, 1996) e Sachs (1993), que são as obras seminais sobre o tema.

A Comissão Brundtland (CMMAD, 1988) afirma que para haver a sustentabilidade ambiental é preciso não pôr em risco os elementos naturais que sustentam a integridade global do ecossistema: a qualidade do ar, dos solos, das águas e dos seres vivos. Encontrar novas tecnologias para reduzir a pressão sobre o meio ambiente, que minimizem o esgotamento e propiciem substitutos para esses recursos.

De acordo com o documento Agenda 21 (CNUMAD, 1996), a sustentabilidade ambiental está relacionada a padrões de consumo e de produção sustentáveis e uma maior eficiência no uso de energia para reduzir, ao mínimo, as pressões ambientais, o esgotamento dos recursos naturais e a poluição. Os governos, em conjunto com setor privado e a sociedade, devem atuar para reduzirem a geração de resíduos e de produtos descartados, por meio da reciclagem, nos processos industriais e na introdução de novos produtos ambientalmente saudáveis. 
Para Sachs (1993),

a sustentabilidade ambiental pode ser alcançada por meio da intensificação do uso dos recursos potenciais ... para propósitos socialmente válidos; da limitação do consumo de combustíveis fósseis e de outros recursos e produtos facilmente esgotáveis ou ambientalmente prejudiciais, substituindo-se por recursos ou produtos renováveis e/ou abundantes e ambientalmente inofensivos; redução do volume de resíduos e de poluição ...; intensificação da pesquisa de tecnologias limpas (p. 23).

No Brasil, são poucos os estudos realizados sobre a produção científica na área de sustentabilidade ambiental que tratam de temas, autores, referências e abordagens metodológicas. Dessa forma, a questão de pesquisa que norteia este estudo é: qual o perfil das pesquisas e a evolução do tema sustentabilidade ambiental nos artigos publicados em periódicos nacionais Qualis de Administração de A1 a B2, no período de 1992 a 2011 ?

A razão deste estudo longitudinal de 20 anos sobre o tema, no Brasil, foi acompanhar a evolução da temática ambiental no período entre as duas grandes conferências ambientais, Rio 92 e a Rio + 20, em periódicos científicos mais qualificados da área de Administração.

Nesse sentido, os artigos analisados estão diretamente relacionados aos temas que concernem à sustentabilidade ambiental, que pode ser considerada um guarda-chuva que abriga artigos sobre a temática meio ambiente, que é o recorte desta pesquisa. Os artigos que tratam apenas da dimensão social e econômica da sustentabilidade isoladamente não foram considerados nesta pesquisa.

Assim, este estudo tem como objetivos investigar o perfil das pesquisas e a evolução do tema sustentabilidade ambiental nos artigos publicados em periódicos nacionais Qualis de Administração de A1 a B2, no período de 1992 a 2011. Trata-se de uma análise bibliométrica, em periódicos Qualis de fator de impacto da área de Administração (Machado-da-Silva, Guarido Filho, Rossoni, \& Graeff, 2008), de A1 a B2.

Tal ação ajudará a revisitar a produção nacional do conhecimento em Administração (Sampaio \& Perin, 2006), mas especificamente em sustentabilidade ambiental. Estimulará pesquisadores e educadores à reflexão sobre as formas, os limites e os critérios pelos quais é produzido e julgado o conhecimento científico no tema ora estudado nesta pesquisa (Bertero, Caldas, \& Wood, 1999).

A estrutura do trabalho está organizada em mais quatro seções, além desta introdutória. Na seção seguinte, são apresentados alguns estudos bibliométricos nacionais e internacionais desenvolvidos sobre o tema. A terceira seção discorre sobre os procedimentos metodológicos adotados no estudo: coleta, análise e tratamento dos dados. A quarta apresenta os resultados da pesquisa e faz a análise e discussão desses resultados. Na última seção, nas considerações finais, são sintetizadas as principais conclusões, apresentadas as limitações da pesquisa e as recomendações para estudos futuros.

\section{Estudos Bibliométricos em Sustentabilidade Ambiental}

No Brasil, as primeiras publicações sobre sustentabilidade ambiental em periódicos da área de administração são da década de 1990 e contribuíram para disseminar o tema. Além dos diversos artigos publicados em periódicos, no final da década de 1980 e início da década de 1990, foram publicados os principais livros e relatórios internacionais (CMMAD, 1988; CNUMAD, 1996; Sachs, 1986, 1993), entre os autores nacionais, destacam-se Maimon (1992, 1994, 1996), Donaire (1994), Barbieri (2001). A partir do início desse século, esse tema consolidou-se nos principais congressos e periódicos da área de administração, surgindo, a partir daí, estudos bibliométricos sobre a produção científica em sustentabilidade ambiental em publicações nacionais e internacionais. 
Schubert e Láng (2005) coletaram, em duas bases bibliográficas multidisciplinares, o Science Citation Index e o Social Science Citation Index, os artigos científicos de revistas publicadas de 1987 a 2001, após a publicação do relatório Nosso Futuro Comum. Assim, verificaram que a palavra sustentabilidade tornou-se tema de trabalhos na área de operações, gestão, tecnologia e urbanização naquele período.

Rosa e Ensslin (2007) exploraram a produção científica em gestão ambiental empresarial, no período compreendido entre os anos de 2005 e 2006. A base de dados utilizada consistiu de artigos publicados nos anais de quatro eventos científicos: Encontro Nacional sobre Gestão Empresarial e Ambiental (ENGEMA); Encontro Nacional da ANPAD (ENANPAD); Simpósio Brasileiro de Pesquisa Operacional (SBPO) e Congresso da USP de Controladoria e Contabilidade. Após a análise de 348 artigos, as autoras concluíram que houve concentração de trabalhos na categoria gestão da sustentabilidade ambiental, seguida pela categoria gestão do plano ambiental, com a inserção da gestão ambiental no âmbito estratégico das empresas e das políticas públicas.

Sgarbi, Lima, Santo e Falcão (2008) buscaram identificar os jargões relacionados ao tema sustentabilidade na produção acadêmica brasileira de administração e engenharia de produção, no período de 2003 a 2007. Os resultados do estudo evidenciaram que, com o passar dos anos, é crescente o número de publicações acerca da sustentabilidade nos anais de congressos, porém é inversamente proporcional quando se trata dos periódicos pesquisados.

Gallon, Rover, Souza e Bellen (2008) traçaram um panorama da produção científica em administração sobre a temática ambiental. Os autores, após a análise de 165 artigos, no período de 2000 a 2006, concluíram que um aspecto positivo nas publicações da área é a perspectiva de inserção internacional. Constataram ainda o uso significativo de livros, produção consolidada, que, para os autores, pode não refletir o estado da arte da temática. Quanto aos eventos, notaram que boa parte das referências não é classificada no Qualis/Capes, o que pode significar baixo impacto dessas citações.

Jabbour, Santos e Barbieri (2008) conduziram uma meta-análise da produção científica em gestão ambiental empresarial, no período entre 1996 e 2005. Os resultados mostraram que a produção acadêmica em gestão ambiental empresarial corresponde a apenas 2,3\% do total em administração, sendo que parte significativa dessa produção fundamenta-se em trabalhos internacionais e restringe-se a um pequeno grupo de pesquisadores e instituições.

Moretti e Campanário (2009) realizaram uma pesquisa sobre o estado da arte das publicações brasileiras na área de responsabilidade social empresarial nos Encontros da Anpad, do período de 1997 a 2007. Os resultados mostram pouca maturidade científica dos autores no tema. Verificaram que a produção dos anos anteriores à análise foi pouco utilizada nos anos seguintes e houve repetição de livros e textos de administração e autores consagrados, mas poucos relacionados ao tema. Constataram também um domínio da reprodução das mesmas ideias, reforçando a noção de que existe, nesta área temática, uma zona de conforto intelectual, que não contribui para o avanço da área.

A. R. Nascimento, Santos, Salotti e Múrcia (2009) desenvolveram uma pesquisa cujo objetivo era identificar e caracterizar a pesquisa em disclosure social e ambiental (DSA), no período de 1997 a 2007. Os resultados da pesquisa indicaram que a temática mais estudada é a ambiental, a análise documental é o principal tipo de estudo e os principais centros de pesquisa estão localizados no Reino Unido, Estados Unidos, Canadá e Nova Zelândia.

Machado, Nascimento e Múrcia (2009) realizaram uma pesquisa empírico-analítica, com o objetivo de descrever a produção científica na área de contabilidade social e ambiental, no Brasil. Para isso, analisaram 80 artigos, no período de 2004 a 2008. Os resultados evidenciam que a maioria dos assuntos enfatiza o disclosure social e/ou ambiental. A maior parte dos artigos valeu-se também da pesquisa documental, constataram, ainda, que $77 \%$ dos autores publicaram apenas uma vez nos periódicos analisados e que não existe uma fundamentação teórica consolidada sobre o tema.

Pato, Sá e Catalão (2009) procuraram configurar o cenário das pesquisas apresentadas na área de educação ambiental, nas reuniões anuais da Associação Nacional de Pós-Graduação e Pesquisa em 
Educação. Constatou-se uma evolução da temática; concentração da produção no eixo sul-sudeste do Brasil e a predominância da abordagem socioambiental. Wezel e Soldat (2009) analisaram a evolução histórica da disciplina científica da agroecologia por meio de uma análise bibliométrica em 711 publicações, desse modo, verificando que o tema agroecologia se expandiu durante os anos de $1970 \mathrm{e}$ 1980; consolidou-se durante a década de 1990 e, na década de 2000, a temática ampliou com novas subáreas de conhecimento.

Uehara, Otero, Martins, Philippi e Mantovani (2010) investigaram a evolução da produção de pesquisas em gestão ambiental na Universidade de São Paulo, concluindo que existe uma tendência de aumento do número de grupos de pesquisa nesta temática, na USP, e que o crescimento dessas pesquisas coincidia com eventos importantes na área ambiental.

Yarime, Takeda e Kajikawa (2010) analisaram quantitativamente os padrões de colaboração no campo emergente da ciência da sustentabilidade. Os principais resultados foram: o número crescente de países que estão se envolvendo na investigação da temática, a colaboração é crescente e tende a ser realizada entre países que estão geograficamente mais próximos.

Pereira, Yen-Tsang, Manzini e Almeida (2011) focalizaram a presença do tema sustentabilidade socioambiental nos artigos do International Journal of Operations \& Production Management e traçaram um paralelo da pesquisa realizada com artigos publicados em periódicos brasileiros relevantes da área de gestão de operações. Uma das conclusões é de que as cocitações envolvendo sustentabilidade socioambiental vêm crescendo, posicionando o tema próximo à discussão de estratégia de manufatura.

Grzebieluckas, Campos e Selig (2012) analisaram a produção científica sobre contabilidade e custos ambientais, no período de 1996 a 2007. Os resultados mostraram que houve um crescimento nas duas temáticas, passando de três estudos, em 1996, para dez, em 2007, totalizando 80 estudos no período. Em geral, a temática custos ambientais ganhou maior atenção por parte dos pesquisadores, representando $61 \%$ contra $39 \%$ dos estudos que abordaram contabilidade ambiental. Constatou-se que, dos 148 autores identificados, treze deles foram responsáveis por $48,75 \%$ do total das publicações.

Chabowski, Mena e Gonzalez-Padron (2011) desenvolveram uma investigação sobre o tema sustentabilidade nas revistas de marketing, de 1958 a 2008 e individuaram que o tema Triple Bottom Line está em evidência em 36 revistas estudadas. Leonidou e Leonidou (2011) identificaram, sintetizaram e avaliaram pesquisas existentes sobre marketing e gestão ambiental. Foi constatado que as temáticas investigadas passaram por uma transformação, evoluindo de uma fase inicial de identificação e exploração a uma fase mais avançada, caracterizada por maior maturidade e rigor. Verificaram que, além do crescimento exponencial da temática, nesta última década, há demasiada fragmentação dos temas.

Percebe-se que a quantidade de pesquisas bibliométricas e meta-análises em sustentabilidade tende a se expandir, surgindo gradativamente estudos específicos em diversas áreas, como de operações, marketing, contabilidade, entre outras. No bojo deste processo, observa-se o crescimento gradativo de estudos sobre a produção científica nos seguintes temas: gestão ambiental, responsabilidade socioambiental, cadeias de suprimentos verdes, disclosure ambiental, contabilidade ambiental e marketing verde.

Acredita-se que o artigo aqui proposto possa contribuir na otimização dos estudos evidenciados anteriormente, proporcionando a possibilidade de reflexão no sentido de como evoluíram os estudos em sustentabilidade ambiental nestes últimos 20 anos. Impactando a posteriori no fomento da discussão e na construção do conhecimento da área (Leite, 2008). 


\section{Procedimentos Metodológicos}

Este estudo caracteriza-se como descritivo, com abordagens qualitativa e quantitativa. Trata-se, também, de um estudo documental (S. Nascimento \& Beuren, 2011), utilizando-se de técnicas de análise bibliométrica (A. R. Nascimento, Junqueira, \& Martins, 2010; Balestrin, Verschoore, \& Reyes, 2010) que se destinam a quantificar e analisar a produção científica do tema (Cooper \& Lindsay, 1998), e sua importância reflete-se na avaliação da pesquisa acadêmica, norteando rumos e estratégias para futuros trabalhos. Estudos deste tipo são também conhecidos como meta-análises (Melo \& Andreassi, 2010).

O planejamento de uma pesquisa de análise bibliométrica passa por quatro etapas importantes, adicionais à etapa de formulação do problema de pesquisa: a escolha da literatura analisada, a avaliação dos dados coletados, a análise e interpretação das informações e a apresentação dos resultados (Cooper \& Lindsay, 1998). Pritchard (1998) afirma que a bibliometria é a medida quantitativa das publicações científicas de um pesquisador ou instituição em periódicos com seleção arbitrada, e a medida qualitativa dessas publicações por meio de indicadores que incluem estudos comparativos de publicações e citações. Além de ajudar no mapeamento de possíveis relações entre pesquisadores (Guarido Filho, Machado-da-Silva, \& Gonçalves, 2010).

É importante salientar que, como disciplina científica, a bibliometria desenvolveu um grupo de leis que referenciam os estudos de forma sistêmica (Moretti \& Campanário, 2009), sendo oriundas, respectivamente, de três pesquisadores que se destacam por suas importantes descobertas, Bradford, Zipf e Lotka (Vanti, 2002), sendo, assim, as mais conhecidas e comumente utilizadas e relacionadas à produtividade e comunicação científica (Bufrem \& Prates, 2005).

A Lei de Bradford ou Lei da Dispersão dos periódicos, criada em janeiro de 1934, por Samuel C. Bradford (Borges, 2002), mensura o grau de atração de periódicos sobre determinada temática. Os periódicos poderão ser divididos em zonas de produtividade, entre elas, a primeira zona constitui o núcleo de periódicos que se integra com a área que está sendo investigada. Em outras palavras, o núcleo essencial de revistas forma a base da literatura para todas as disciplinas, sendo, portanto, a maioria dos trabalhos importantes publicada em poucas revistas (Testa, 1998), que são os periódicos de maior fator de impacto. Já a Lei de Zipf, ou Lei do Mínimo Esforço, mensura a quantidade de ocorrências do aparecimento das palavras em vários textos, dessa maneira, gerando uma lista ordenada de termos de uma determinada temática, utilizada para verificar qual tema científico é tratado nas publicações (Moretti \& Campanário, 2009).

E, por último, a Lei do Quadrado Inverso, formulada por Lotka, em 1926, que rege o crescimento da literatura produzida por meio de um modelo de distribuição de tamanho-frequência da produtividade dos autores em um conjunto de publicações (Urbizagastegui, 2009). Neste contexto, ressalta-se que essa lei se aplica a grandes volumes de publicações em área científica consolidada, como é o caso da área de administração.

Ao evidenciar a produtividade de autores, surgem os colégios invisíveis. Esses colégios constituíam-se de comunidades informais de pesquisadores os quais se comunicavam, trocavam informações e experiências, publicando formalmente seus resultados no campo do saber (Balancieri, Bovo, Kern, Pacheco, \& Barcia, 2005; Vanz \& Stumpf, 2010).

A escolha de qual literatura será analisada é um dos pontos-chave de análise desses gêneros, pois define o escopo do estudo e pode impactar sua validade (Singleton \& Straits, 1999). Nesta pesquisa, como o objetivo é analisar a produção nacional sobre o tema, foi escolhida uma amostra de periódicos nacionais relevantes, utilizando a classificação Qualis, da Coordenação de Aperfeiçoamento de Pessoal no Nível Superior (Capes). A listagem conhecida como Qualis é uma lista de veículos utilizados para a divulgação da produção intelectual dos programas de pós-graduação stricto sensu, mestrado e doutorado, classificados quanto ao âmbito de circulação e à qualidade (A, B, C), por área de avaliação (CAPES, 2011). 
$\mathrm{Na}$ área de Administração, Ciências Contábeis e Turismo, há 837 periódicos de A1 a C (nacionais e internacionais) classificados pela Qualis (Capes, 2011). Foram escolhidos os periódicos (nacionais) classificados como A1, A2, B1 e B2 pela Qualis da área de Administração, no triênio 2007-2009. Essa faixa representa o estrato superior de avaliação e corresponde a vinte periódicos, o que equivale a 2,39\% de todos os periódicos da área de Administração, Ciências Contábeis e Turismo, listados na Tabela 1. Na área de Administração, Ciências Contábeis e Turismo não foram encontrados periódicos A1, sendo assim, as revistas analisadas estão no estrato de A2 a B2, como mostra a Tabela 1.

Tabela 1

Classificação de Revistas pelo Critério do Qualis da Área de Administração, no triênio 20072009

\begin{tabular}{lcccc}
\hline Título do Periódico & SIGLA $^{\text {a }}$ & ISSN & Categoria & Qualis \\
\hline Brazilian Administration Review & BAR & $1807-7692$ & Nacional & A2 \\
Gestão \& Produção & G\&P & $0104-530 x$ & Nacional & A2 \\
Produção & Produção & $0103-6513$ & Nacional & A2 \\
Revista de Administração Pública & RAP & $0034-7612$ & Nacional & A2 \\
Cadernos EBAPE & EBAPE & $1679-3951$ & Nacional & B1 \\
RAC-Eletrônica & RAC-e & $1981-5700$ & Nacional & B1 \\
Revista de Administração de Empresas & RAE & $0034-7590$ & Nacional & B1 \\
RAE-Eletrônica & RAE-e & $1676-5648$ & Nacional & B1 \\
Revista de Administração Contemporânea & RAC & $1415-6555$ & Nacional & B1 \\
Revista de Administração Mackenzie & RAM & $1518-6776$ & Nacional & B1 \\
Revista Brasileira de Finanças & RBF & $1679-0731$ & Nacional & B1 \\
Revista de Contabilidade \& Finanças & RCF & $1519-7077$ & Nacional & B1 \\
Brazilian Business Review & BBR & $1807-734 x$ & Nacional & B2 \\
Organizações \& Sociedade & O\&S & $1413-585 x$ & Nacional & B2 \\
Organizações Rurais e Agroindustriais & ORA & $1517-3879$ & Nacional & B2 \\
RAUSP-Eletrônica & RAUSP-e & $1983-7488$ & Nacional & B2 \\
Revista Eletrônica de Administração & REAd & $1413-2311$ & Nacional & B2 \\
Revista BASE & BASE & $1807-054 x$ & Nacional & B2 \\
Revista de Administração da USP & RAUSP & $0080-2107$ & Nacional & B2 \\
Revista de Gestão da Tecnologia e Sistemas de Informação & RGTSI & $1809-2640$ & Nacional & B2 \\
\hline Nota A mas & & &
\end{tabular}

Nota. A maioria das revistas tem a sua sigla, para algumas foram criadas siglas para serem utilizadas nas figuras. Fonte: Coordenação de Aperfeiçoamento de Pessoal de Nível Superior. (2011). Revistas Qualis. Recuperado de http://www.capes.gov.br/avaliacao/qualis

É importante salientar que, apesar da Revista de Gestão Social e Ambiental (RGSA) ser o periódico mais importante da área socioambiental em Administração, não foi avaliada por não estar classificada no estrato A1 a B2 no triênio (2007-2009), contudo, na nova classificação da Capes (2010-2012), divulgada em 2012, a Revista recebeu a classificação B2.

A coleta de dados foi realizada em artigos publicados no período de 1992 a 2011, o que corresponde a um levantamento longitudinal de vinte anos. Das revistas pesquisadas, apenas na RAP a busca foi feita em exemplares disponíveis em biblioteca no período de 1992 a 1999, nas demais, a 
pesquisa foi realizada nas edições disponíveis em seus respectivos sites ou em base de dados, como a Scielo, de fácil acesso e consulta.

Para selecionar os artigos, foi realizada a leitura de 7.368 títulos das vinte revistas investigadas, desse total, foram encontrados 396 artigos que tratam de temas relacionados à sustentabilidade ambiental. Esses artigos foram agrupados em 25 categorias que emergiram na análise dos títulos, palavras-chave e resumo, tomando como base a classificação de Souza, Machado, Parisotto e Silva (2011). Os critérios utilizados para criar e nomear estas categorias estão relacionados aos instrumentos e ferramentas de gestão ambiental, a áreas de conhecimento e a temas mais abrangentes quando não foi possível a classificação em subtemas específicos.

As categorias relacionadas aos principais instrumentos e ferramentas de Gestão Ambiental foram: Cadeia de Suprimentos Verde; Ecodesign; Ecoeficiência; Educação Ambiental; Marketing Verde; Gestão de Resíduos; Inovação ambiental; Mecanismo de Desenvolvimento Limpo; Produção mais Limpa; Rotulagem Ambiental e Sistema de Gestão Ambiental. O outro grupo de categoria está relacionado a áreas do conhecimento, como: Contabilidade Ambiental, Turismo Sustentável, Economia Ambiental, Legislação Ambiental e Políticas Públicas Ambientais; Agricultura e Meio Ambiente. Além dessas categorias, foram criadas categorias mais amplas para classificar artigos que não se enquadraram nas categorias mencionadas, entre elas: Desenvolvimento Sustentável; Sustentabilidade Empresarial; Responsabilidade Socioambiental; Gestão Ambiental; Conflito Socioambiental; Movimento Ambientalista; Recursos Hídricos; e Energias Alternativas.

É importante ressaltar que há diversas maneiras de agrupar os artigos em categorias, "que são rubricas ou classes, as quais reúnem um grupo de elementos sob um título genérico, efetuado em razão das características comuns destes elementos" (Bardin, 2009, p. 145). Neste estudo, a opção foi não agrupar os diversos subtemas dos artigos analisados para evidenciar as temáticas priorizadas nas pesquisas da área.

Os artigos selecionados foram catalogados pelos softwares Mendeley Desktop e Microsoft Excel. A análise dos indicadores apresentada no item a seguir foi feita de forma quantitativa, utilizando-se estatística descritiva.

\section{Apresentação, Análise e Discussão dos Resultados da Pesquisa}

A análise bibliométrica dos resultados da pesquisa realizada nos 396 artigos foi subdividida em cinco tópicos: periódicos de destaque; evolução dos temas; abordagens metodológicas; características de autoria; e referências bibliográficas utilizadas nos artigos.

\section{Periódicos de destaque}

A Figura 1 mostra o número de artigos publicado sobre o tema sustentabilidade ambiental, no período de 1992 a 2011. 


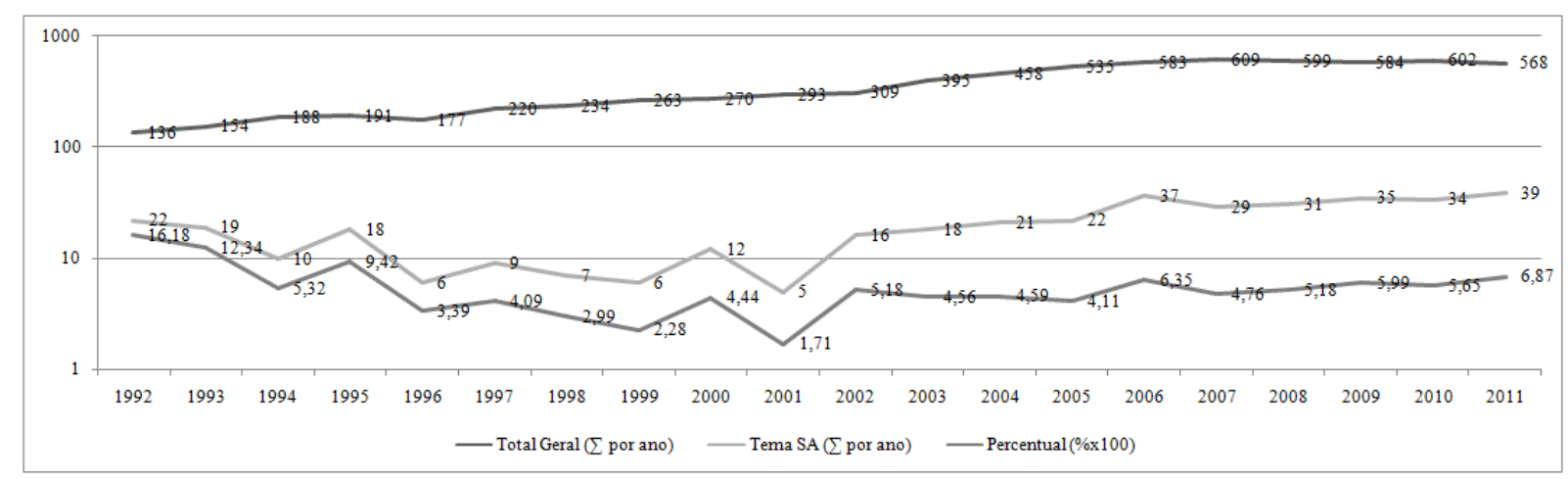

Figura 1. Evolução do Número de Artigos sobre Sustentabilidade Ambiental por Ano. Escala Logarítmica. Fonte: Dados da pesquisa.

Ao analisar a Figura 1, percebe-se que os anos de 1992, 1993 e 1995 foram atípicos. A explicação para o crescimento das publicações em 1992 foi a edição de um número da RAP sobre a temática, em razão da repercussão das discussões em torno da Rio-92, que atingiu não só os veículos de comunicação em massa, como também periódicos científicos. Já o aumento de artigos em 1995 pode ser explicado pela intensa discussão em torno das mudanças climáticas com realização da COP1, que levou à publicação de mais dois números voltados ao tema na RAP e RAE. A partir daí, o crescimento estabiliza, no início dos anos 2000. Esse fato, reforçam os resultados da pesquisa de Uehara et al. (2010), que constataram uma correlação entre o crescimento de pesquisas na área ambiental com os marcos históricos.

Em 2001, houve uma queda acentuada de estudos relacionados à temática, por sua vez, a partir de 2002, deu-se um aumento de artigos publicados sobre sustentabilidade ambiental, mas, proporcionalmente ao número total publicado no período, nota-se um pequeno crescimento até 2011. O percentual médio de publicações sobre a temática em questão, durante os vinte anos pesquisados, foi de $5,77 \%$, do montante dos 7.368 artigos das vinte revistas investigadas.

A Tabela 2 complementa as informações da Figura 1, assinalando o número de artigos sobre sustentabilidade ambiental, por revista, em cada ano pesquisado e o destaque das edições especiais ou números dedicados à temática.

Tabela 2

\section{Número de Artigos por Revista}

\begin{tabular}{|c|c|c|c|c|c|c|c|c|c|c|c|c|c|c|c|c|c|c|c|c|c|c|}
\hline Revistas/anos & 92 & 93 & 94 & 95 & 96 & 97 & 98 & 99 & $\mathbf{0 0}$ & 01 & 02 & $\mathbf{0 3}$ & 04 & 05 & 06 & 07 & 08 & 09 & 10 & 11 & Total & $\%$ \\
\hline RAP & 19 & 9 & 1 & 6 & 3 & 4 & 3 & 2 & 4 & 1 & 1 & 5 & 5 & 1 & 7 & 3 & 2 & 2 & 2 & 5 & 85 & $21,5 \%$ \\
\hline REAd & & & & & & & & 1 & 4 & 2 & 8 & 6 & 2 & 3 & 2 & 2 & 3 & 5 & 1 & 2 & 41 & $10,4 \%$ \\
\hline $\mathrm{RAE}+\mathrm{RAE}-\mathrm{e}$ & 3 & 5 & 7 & 7 & & 1 & & & 3 & & 2 & 2 & 1 & 1 & & 1 & 1 & 1 & 3 & 2 & 40 & $10,1 \%$ \\
\hline G\&P & & & & & & & & & & & 1 & & & & 16 & 2 & 4 & 4 & 6 & 4 & 37 & $9,3 \%$ \\
\hline Produção & & 1 & 1 & 1 & 1 & & 1 & 1 & & & & 2 & 1 & 1 & 2 & 3 & 2 & 2 & 6 & 8 & 33 & $8,3 \%$ \\
\hline ORA & & & & & 1 & 1 & & & & & 2 & 1 & 1 & 1 & 3 & 4 & 4 & 6 & 4 & 2 & 30 & $7,6 \%$ \\
\hline EBAPE & & & & & & & & & & & & & 4 & 11 & 1 & 2 & 2 & 2 & 2 & 2 & 26 & $6,6 \%$ \\
\hline $\mathrm{RAC}+\mathrm{RAC}-\mathrm{e}$ & & & & & & & 1 & 1 & & & 1 & & 1 & 1 & 1 & 4 & 6 & 4 & 1 & & 21 & $5,3 \%$ \\
\hline Rausp + Rausp-e & & 2 & 1 & 2 & 1 & 2 & 1 & & 1 & & & 1 & 1 & 1 & & 3 & 1 & 1 & 1 & 2 & 21 & $5,3 \%$ \\
\hline O\&S & & & & 1 & & 1 & & 1 & & & 1 & 1 & & 1 & & 2 & 3 & 1 & 5 & 1 & 18 & $4,5 \%$ \\
\hline
\end{tabular}


Tabela 2 (continuação)

\begin{tabular}{|c|c|c|c|c|c|c|c|c|c|c|c|c|c|c|c|c|c|c|c|c|c|c|}
\hline Revistas/anos & 92 & 93 & 94 & 95 & 96 & 97 & 98 & 99 & 00 & 01 & 02 & $\mathbf{0 3}$ & 04 & 05 & 06 & 07 & 08 & 09 & 10 & 11 & Total & $\%$ \\
\hline RAM & & & & & & & & & & 1 & & & 2 & & 2 & & 1 & 3 & 1 & 7 & 17 & $4,3 \%$ \\
\hline $\mathrm{RCF}$ & & 2 & & 1 & & & 1 & & & 1 & & & 2 & & & 2 & 1 & 1 & & 2 & 13 & $3,3 \%$ \\
\hline BBR & & & & & & & & & & & & & 1 & & 3 & & 1 & 1 & & & 6 & $1,5 \%$ \\
\hline BAR & & & & & & & & & & & & & & 1 & & 1 & & 1 & & 1 & 4 & $1,0 \%$ \\
\hline BASE & & & & & & & & & & & & & & & & & & 1 & 1 & 1 & 3 & $0,8 \%$ \\
\hline RGTSI & & & & & & & & & & & & & & & & & & & 1 & & 1 & $0,3 \%$ \\
\hline $\mathrm{RBF}$ & & & & & & & & & & & & & & & & & & & & & 0 & $0,0 \%$ \\
\hline Total & 22 & 19 & 10 & 18 & 6 & 9 & 7 & 6 & 12 & 5 & 16 & 18 & 21 & 22 & 37 & 29 & 31 & 35 & 34 & 39 & 396 & $100,0 \%$ \\
\hline
\end{tabular}

Nota. As revistas RAE Eletrônica (RAE-e), RAC Eletrônica (RAC-e) e RAUSP Eletrônica (RAUSP-e) foram extintas e, por esse motivo, aparecem na somatória da RAE, RAC e RAUSP, respectivamente. Fonte: Dados da pesquisa.

Anos em que os periódicos ainda não existiam; Anos com edições especiais.

Observa-se que mais da metade, ou seja, 59,6\% dos artigos publicados estão concentrados nas cinco primeiras revistas: Revista de Administração Pública (RAP), Revista Eletrônica de Administração (REAd), Revista de Administração de Empresas (RAE), Gestão \& Produção (G\&P) e Produção. Esses resultados corroboram a Lei de Bradford (Testa, 1998) sobre o núcleo de revistas que forma a base da literatura em determinada área, com poucos periódicos de maior fator de impacto.

Os Cadernos EBAPE.BR publicaram onze artigos, em 2005, ou seja, 42\% de todos os artigos do periódico na área no ano. Enquanto a revista Gestão \& Produção começou a publicar artigos sobre sustentabilidade ambiental a partir de 2006, com dezesseis artigos em uma edição especial lançada no ano. A RAP, também em 2006, teve sete publicações sobre sustentabilidade ambiental, porém, nos anos de 1993 e, principalmente, 1992, a RAP teve um volume maior de artigos sobre a temática, com nove e dezenove publicações, respectivamente, devido a edições especiais, em decorrência da Rio-92.

É interessante notar que, das cinco revistas que mais publicaram, duas tiveram o ápice nos anos de 2005 e 2006. As edições especiais sobre o tema justificam esse crescimento e coincidem com acontecimentos internacionais de grande impacto, como a ratificação do Protocolo de Kyoto, em agosto de 2005.

A Figura 2 complementa as informações da Figura 1 e da Tabela 2, ao descrever o total geral de artigos por revista comparado com o número de artigos sobre sustentabilidade ambiental no período analisado, mostrando uma nova perspectiva em relação aos mesmos dados. 


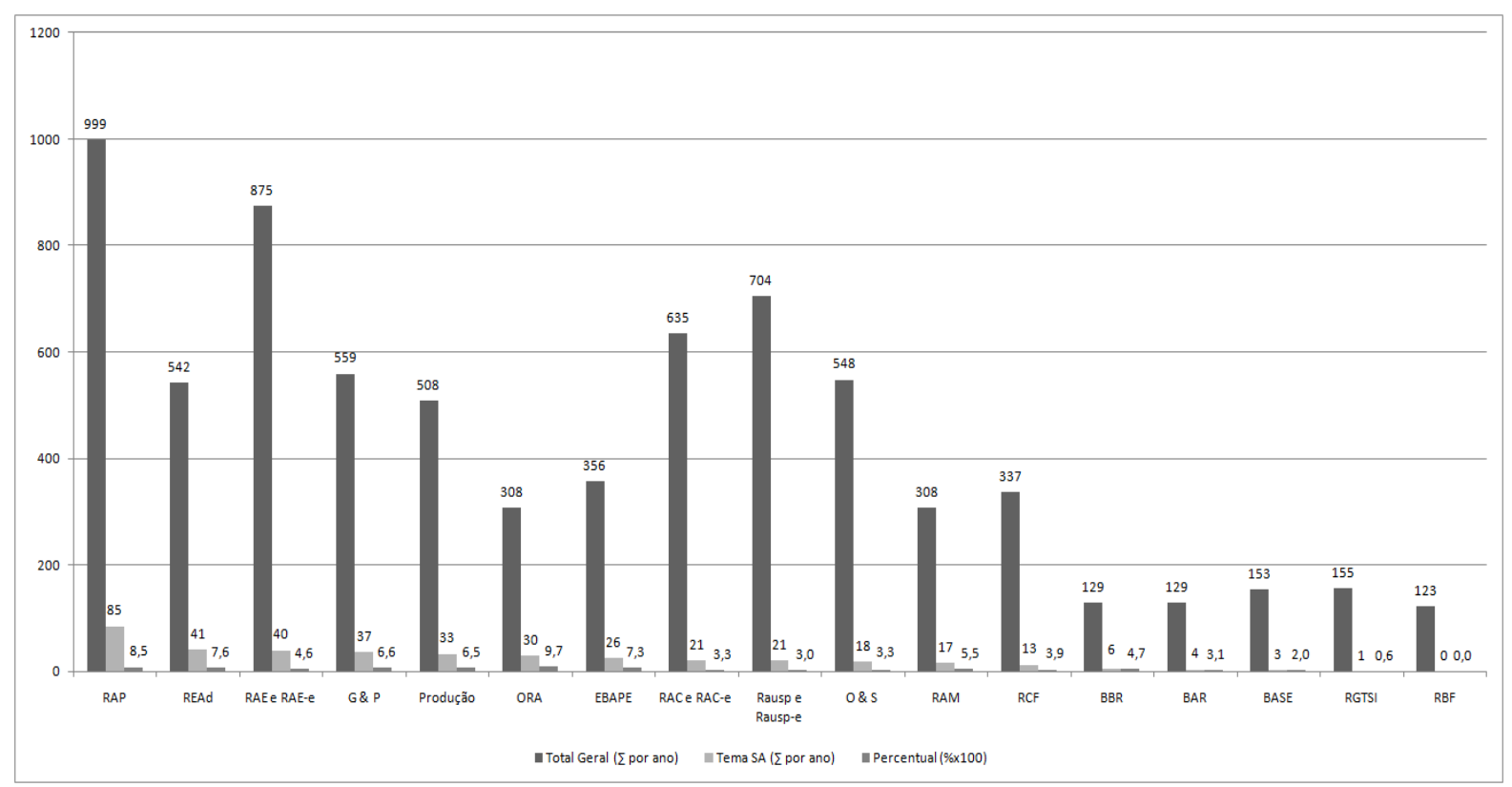

Figura 2. Número Total de Artigos por Revista Comparado com o Total de Artigos sobre Sustentabilidade Ambiental.

Fonte: Dados da pesquisa.

As revistas Organizações Rurais e Agroindustriais (9,7\%), Revista de Administração Pública (8,5\%), Revista Eletrônica de Administração (7,6\%) e Cadernos Ebape (7,3\%), G\&P (6,6\%) e Produção $(6,5 \%)$ destacam-se em relação ao percentual de artigos publicados no tocante ao tema sustentabilidade ambiental em comparação com o número total de publicações de periódicos. $\mathrm{O}$ crescimento da temática em duas revistas ligadas à área de operações, ou seja, a Gestão \& Produção e a Produção, confirma os resultados encontrados por Pereira et al. (2011).

\section{Evolução dos temas}

A análise das temáticas pode ser vista como fator preponderante para continuidade das pesquisas, proporcionando um norte para pesquisadores experientes e, principalmente, para os iniciantes, o que influencia o crescimento e a disseminação de futuras pesquisas. Na Tabela 3, elencase a frequência dos temas com maior número de artigos que tratam de sustentabilidade ambiental por revista. 
Tabela 3

\section{Temas por Revistas}

\begin{tabular}{|c|c|c|c|c|c|c|c|c|c|c|c|c|c|c|c|c|c|c|}
\hline Temas/Revistas & RAP & REAd & $\begin{array}{l}\text { RAE e } \\
\text { RAE-e }\end{array}$ & G\& P & Prod. & ORA & EBAPE & $\begin{array}{l}\text { RAC e } \\
\text { RAC-e }\end{array}$ & $\begin{array}{l}\text { Rausp e } \\
\text { Rausp-e }\end{array}$ & O\&S & RAM & $\mathbf{R C F}$ & BBR & BAR & BASE & RGTSI & $\mathbf{R B F}$ & Total \\
\hline Gestão ambiental & 11 & 6 & 11 & 5 & 7 & 4 & 4 & 2 & 6 & 6 & 4 & & & & & & & 66 \\
\hline Desenvolvimento sustentável & 9 & 4 & 5 & 1 & 2 & 2 & 4 & & & 3 & 1 & & & 1 & & & & 32 \\
\hline Gestão de resíduos & 5 & 2 & 1 & 6 & 4 & 1 & 5 & 2 & 1 & 1 & 1 & & & & & & & 29 \\
\hline Recursos hídricos & 15 & 3 & 2 & 1 & & 2 & 2 & 1 & 1 & 2 & & & & & & & & 29 \\
\hline Contabilidade ambiental & 1 & & 3 & & 3 & & 1 & 2 & & & 1 & 11 & 2 & & 1 & 1 & & 26 \\
\hline Marketing verde & 2 & 3 & 1 & & 2 & 3 & 1 & 1 & 5 & & 4 & & & 1 & & & & 23 \\
\hline Sistema de gestão ambiental & 3 & 5 & 2 & 6 & 3 & 1 & 1 & 2 & & & & & & & & & & 23 \\
\hline Responsabilidade socioambiental & 1 & 4 & 1 & 3 & & 3 & & 2 & & 1 & & & 1 & 1 & 1 & & & 18 \\
\hline Inovação ambiental & 4 & 2 & 1 & 2 & 3 & & 2 & 1 & & & 1 & & & & & & & 16 \\
\hline Sustentabilidade empresarial & & 1 & 2 & 2 & 1 & & 1 & 1 & 2 & & 2 & 2 & & & 1 & & & 15 \\
\hline Mecanismo de desenvol. limpo & 3 & 2 & & 2 & & 2 & 1 & & 1 & 2 & & & & & & & & 13 \\
\hline Agricultura e meio ambiente & 2 & 1 & 1 & & & 5 & & 2 & 1 & 1 & & & & & & & & 13 \\
\hline Políticas públicas ambientais & 9 & & 1 & & & & 1 & & & & & & & & & & & 11 \\
\hline Cadeia de suprimentos verde & & 1 & 1 & 3 & 3 & & & & 1 & & & & 1 & & & & & 10 \\
\hline Energias alternativas & & & 4 & & 2 & 3 & & & & & & & 1 & & & & & 10 \\
\hline Turismo sustentável & 5 & & & & & & 1 & 2 & 1 & & & & & 1 & & & & 10 \\
\hline Rotulagem ambiental & 1 & 1 & & & & 4 & & & 2 & & 1 & & & & & & & 9 \\
\hline Produção mais limpa & & & 1 & 4 & 2 & & & 1 & & & & & & & & & & 8 \\
\hline Legislação ambiental & 3 & 2 & 1 & & & & 1 & & & 1 & & & & & & & & 8 \\
\hline Movimento ambientalista & 3 & 1 & & 1 & & & 1 & & & 1 & & & & & & & & 7 \\
\hline Conflito socioambiental & 5 & 1 & & & & & & 1 & & & & & & & & & & 7 \\
\hline
\end{tabular}


Tabela 3 (continuação)

\begin{tabular}{|c|c|c|c|c|c|c|c|c|c|c|c|c|c|c|c|c|c|c|}
\hline Temas/Revistas & RAP & REAd & $\begin{array}{l}\text { RAE e } \\
\text { RAE-e }\end{array}$ & G\& P & Prod. & ORA & EBAPE & $\begin{array}{l}\text { RAC e } \\
\text { RAC-e }\end{array}$ & $\begin{array}{l}\text { Rausp e } \\
\text { Rausp-e }\end{array}$ & O\&S & RAM & RCF & BBR & BAR & BASE & RGTSI & RBF & Total \\
\hline Educação ambiental & 3 & & 1 & & & & & & & & 2 & & & & & & & 6 \\
\hline Ecodesign & & 1 & & 1 & 1 & & & & & & & & & & & & & 3 \\
\hline Economia ambiental & & & 1 & & & & & 1 & & & & & & & & & & 2 \\
\hline Ecoeficiência & & 1 & & & & & & & & & & & 1 & & & & & 2 \\
\hline Total & 85 & 41 & 40 & 37 & 33 & 30 & 26 & 21 & 21 & 18 & 17 & 13 & 6 & 4 & 3 & 1 & $\mathbf{0}$ & 396 \\
\hline
\end{tabular}

Fonte: Dados da pesquisa. 
A Tabela 3 foi analisada de acordo com a Lei de Bradford (Moretti \& Campanário, 2009), que mede o grau de atração dos periódicos sobre determinado tema, verificando, assim, o núcleo de periódicos que é utilizado para a comunicação dos trabalhos. Assim, foi possível individuar que a temática Gestão Ambiental se destaca nos periódicos: RAP (11), RAE (11) e Produção (7). O tema desenvolvimento sustentável teve mais publicações na RAP, nove; seguido das revistas, RAE, com cinco; Revista Eletrônica de Administração e Cadernos Ebape, ambas com quatro artigos publicados. Já o tema Gestão de Resíduos teve mais artigos publicados na Gestão \& Produção, seis; Revista de Administração Pública, cinco; Cadernos Ebape, cinco; seguido da revista Produção, quatro. Vale ressaltar que o enfoque desses dois periódicos ( $\mathrm{G} \& \mathrm{P}$ e Produção) é a área de produção, que tem maior sinergia com o tema Gestão de Resíduos. No que se refere ao tema Recursos Hídricos, destaca-se a RAP, por ser um tema relacionado à área de administração pública, com quinze artigos, sendo nove deles no ano de 1993 devido a uma edição especial (Tabela 2).

O tema contabilidade ambiental predominou na Revista Contabilidade \& Finanças (onze), com $42 \%$ das publicações, seguida pelas revistas RAE e Produção, ambas com três artigos. O tema marketing verde teve destaque principal em dois periódicos: Revista de Administração da USP (cinco) e Revista de Administração Mackenzie (quatro). Enquanto a temática sistema de gestão ambiental foi predominante nas revistas Gestão \& Produção (seis); seguida da REAd (cinco), pelo fato desses artigos tratarem da norma NBR ISO 14001, que a implementação está diretamente ligada à área de operações, que é o foco do periódico G\&P, e conteúdo de destaque da REAd.

Pode-se constatar também uma relação dos demais temas com os periódicos, tais como inovação ambiental, mecanismos de desenvolvimento limpo, políticas públicas ambientais, turismo sustentável, legislação ambiental, movimento ambientalista e conflito socioambiental, todos privilegiados na Revista de Administração Pública. Já o tema responsabilidade socioambiental destaca-se na revista REAd. A temática energia alternativa relaciona-se mais com a RAE. Em relação aos temas cadeias de suprimento verde e produção mais limpa, sobressaem-se nas revistas Produção e G\&P. Já a revista Organizações Rurais e Agroindustriais teve uma forte relação com as temáticas agricultura e meio ambiente e rotulagem ambiental, predominando os artigos sobre produtos orgânicos.

De acordo com a Lei de Bradford (Moretti \& Campanário, 2009), à medida que as primeiras publicações sobre uma nova temática são escritas, elas são submetidas a uma pequena seleção de revistas e, se são legitimadas pela academia, essas revistas fomentam tais publicações, influenciando no desenvolvimento do tema. Em continuidade, outros periódicos começam a publicar sobre o assunto, surgindo assim um núcleo de periódicos mais prolífero em termos de publicação sobre o determinado tema (Borges, 2002). Para melhor fomentar a análise, a Tabela 4 contempla os temas com o ano de publicação. 
Tabela 4

\section{Temas em Destaque por Ano}

\begin{tabular}{|c|c|c|c|c|c|c|c|c|c|c|c|c|c|c|c|c|c|c|c|c|c|c|}
\hline Temas/Anos & 92 & 93 & 94 & 95 & 96 & 97 & 98 & 99 & $\mathbf{0 0}$ & 01 & 02 & $\mathbf{0 3}$ & 04 & 05 & 06 & 07 & 08 & 09 & 10 & 11 & Total & $\%$ \\
\hline Gestão ambiental & 8 & 2 & 3 & 3 & 3 & 1 & & 3 & 2 & 1 & 5 & 2 & 2 & 4 & 6 & 2 & 3 & 6 & 5 & 5 & 66 & $16,7 \%$ \\
\hline Desenvolvimento sustentável & 3 & 2 & 2 & 3 & & 1 & & & 2 & & 1 & 2 & 1 & 1 & 2 & 2 & 3 & 2 & 2 & 3 & 32 & $8,1 \%$ \\
\hline Gestão de resíduos & & & & 1 & & & 2 & 1 & 2 & & 1 & 2 & 2 & & 5 & 3 & 1 & 3 & 3 & 3 & 29 & $7,3 \%$ \\
\hline Recursos hídricos & & 10 & 2 & 1 & & 1 & 1 & 1 & & & & & 2 & 3 & 2 & 2 & 1 & 1 & 2 & & 29 & $7,3 \%$ \\
\hline Contabilidade ambiental & & 2 & & 1 & & 1 & 1 & & & 1 & 1 & & 4 & 2 & 3 & 3 & & 2 & 2 & 3 & 26 & $6,6 \%$ \\
\hline Marketing verde & & 1 & & & & & & & 1 & 1 & 2 & 3 & 1 & 2 & 2 & 1 & & 4 & & 5 & 23 & $5,8 \%$ \\
\hline Sistema de gestão ambiental & 1 & & 1 & 1 & & & 1 & & & 1 & 1 & 1 & 2 & 2 & 3 & 1 & 2 & 1 & 3 & 2 & 23 & $5,8 \%$ \\
\hline Responsabilidade socioambiental & & & & & & & & & & & 2 & 1 & 1 & & & 2 & 5 & 4 & 1 & 2 & 18 & $4,5 \%$ \\
\hline Inovação ambiental & & & 1 & & & 1 & & & & & 1 & & & 2 & 1 & 2 & 3 & & 3 & 2 & 16 & $4,0 \%$ \\
\hline Sustentabilidade empresarial & & 1 & & 1 & & & & & & & & & 1 & & 1 & 1 & 2 & 2 & 3 & 3 & 15 & $3,8 \%$ \\
\hline Mecanismo de desenv. limpo & & & & & & & & & & & & & & & & 1 & 2 & 3 & 3 & 4 & 13 & $3,3 \%$ \\
\hline Agricultura e meio ambiente & 1 & & & 1 & 1 & 1 & & & & & & & 1 & & 1 & 4 & 2 & & 1 & & 13 & $3,3 \%$ \\
\hline Políticas públicas ambientais & 5 & & 1 & & 1 & 1 & & & 2 & & & & & 1 & & & & & & & 11 & $2,8 \%$ \\
\hline Cadeia de suprimentos verde & & & & & & & & & & & & 1 & & & 5 & 2 & & 1 & 1 & & 10 & $2,5 \%$ \\
\hline Energias alternativas & & & & 2 & & & & & 1 & & 1 & & & & & & 1 & 2 & & 3 & 10 & $2,5 \%$ \\
\hline Turismo sustentável & & & & 1 & & 1 & 1 & & & & & & 1 & 3 & 1 & & 1 & & 1 & & 10 & $2,5 \%$ \\
\hline Rotulagem ambiental & & & & 1 & 1 & & & & 1 & & & & 1 & & & 1 & 2 & 1 & 1 & & 9 & $2,3 \%$ \\
\hline Produção mais limpa & & & & & & & & 1 & & & & 1 & & & 2 & 2 & & 1 & 1 & & 8 & $2,0 \%$ \\
\hline Legislação ambiental & 1 & & & 1 & & 1 & & & & & & 2 & & 1 & & & 1 & & & 1 & 8 & $2,0 \%$ \\
\hline Movimento ambientalista & 2 & & & & & & & & & 1 & & & 1 & 1 & & & & 1 & 1 & & 7 & $1,8 \%$ \\
\hline
\end{tabular}


Tabela 4 (continuação)

\begin{tabular}{|c|c|c|c|c|c|c|c|c|c|c|c|c|c|c|c|c|c|c|c|c|c|c|}
\hline Temas/Anos & 92 & 93 & 94 & 95 & 96 & 97 & 98 & 99 & 00 & 01 & 02 & 03 & 04 & 05 & 06 & 07 & 08 & 09 & 10 & 11 & Total & $\%$ \\
\hline Conflito socioambiental & & & & 1 & & & & & & & & 3 & & & 1 & & 1 & & & 1 & 7 & $1,8 \%$ \\
\hline Educação ambiental & 1 & & & & & & 1 & & & & & & 1 & & & & & 1 & & 2 & 6 & $1,5 \%$ \\
\hline Ecodesign & & & & & & & & & & & 1 & & & & 1 & & & & 1 & & 3 & $0,8 \%$ \\
\hline Economia ambiental & & 1 & & & & & & & & & & & & & & & 1 & & & & 2 & $0,5 \%$ \\
\hline Ecoeficiência & & & & & & & & & 1 & & & & & & 1 & & & & & & 2 & $0,5 \%$ \\
\hline Total & 22 & 19 & 10 & 18 & 6 & 9 & 7 & 6 & 12 & 5 & 16 & 18 & 21 & 22 & 37 & 29 & 31 & 35 & 34 & 39 & 396 & $100 \%$ \\
\hline
\end{tabular}

Nota. Fonte: Dados da pesquisa. 
Ao analisar a Tabela 4, observa-se que os temas gestão ambiental e desenvolvimento sustentáveis são os que se destacam há mais tempo, seguidos de gestão de resíduos, recursos hídricos e contabilidade ambiental, marketing verde, sistemas de gestão ambiental, responsabilidade socioambiental e sustentabilidade empresarial.

Os dados da pesquisa vão ao encontro dos resultados de Leonidou e Leonidou (2011), que evidenciaram a fragmentação da área em subtemas e de Wezel e Soldat (2009), que mostram também o crescimento de subáreas, a partir de 2000 , em suas pesquisas.

Vale ressaltar que a evolução da temática, de 2005 a 2011, pode ter sido influenciada pelos seguintes marcos internacionais e nacionais: a ratificação do Protocolo de Quioto e criação pela BM\&F Bovespa do Índice de Sustentabilidade Empresarial (ISE), em 2005, o que justifica também o surgimento do tema Mecanismo de Desenvolvimento Limpo, a partir de 2007, ou seja, dois anos após aprovação do Protocolo de Quioto.

Esses resultados reforçam, em parte, as pesquisas de Chabowski et al. (2011) e revelam o amadurecimento da área com o crescimento do número de artigos e o surgimento de novas temáticas investigadas.

\section{Abordagens metodológicas}

Este item analisa as abordagens metodológicas mais utilizadas nos artigos, o que evidencia a preferência por determinados métodos na área, como mostra a Tabela 5. 
Tabela 5

\section{Tipologia de Pesquisa quanto à Abordagem por Ano}

\begin{tabular}{|c|c|c|c|c|c|c|c|c|c|c|c|c|c|c|c|c|c|c|c|c|c|c|}
\hline Tipo de Pesquisa/Ano & 92 & 93 & 94 & 95 & 96 & 97 & 98 & 99 & 00 & 01 & $\mathbf{0 2}$ & 03 & 04 & 05 & 06 & 07 & 08 & 9 & 10 & 11 & Total & $\%$ \\
\hline Qualitativa & 17 & 17 & 9 & 16 & 3 & 8 & 7 & 5 & 11 & 4 & 12 & 14 & 12 & 11 & 19 & 11 & 14 & 14 & 13 & 16 & 233 & $58,84 \%$ \\
\hline Pesquisa bibliográfica & 17 & 15 & 9 & 15 & 2 & 8 & 5 & 2 & 9 & 1 & 8 & 5 & 6 & 2 & 4 & 3 & 5 & 2 & 1 & 1 & 120 & $30,30 \%$ \\
\hline Estudo de caso & 0 & 1 & 0 & 0 & 0 & 0 & 2 & 3 & 1 & 2 & 3 & 9 & 5 & 3 & 13 & 8 & 5 & 8 & 9 & 11 & 83 & $20,96 \%$ \\
\hline Pesquisa documental & 0 & 1 & 0 & 1 & 1 & 0 & 0 & 0 & 1 & 0 & 1 & 0 & 1 & 6 & 2 & 0 & 3 & 1 & 1 & 1 & 20 & $5,05 \%$ \\
\hline Análise de conteúdo & 0 & 0 & 0 & 0 & 0 & 0 & 0 & 0 & 0 & 1 & 0 & 0 & 0 & 0 & 0 & 0 & 1 & 3 & 2 & 1 & 8 & $2,02 \%$ \\
\hline Pesquisa etnográfica & 0 & 0 & 0 & 0 & 0 & 0 & 0 & 0 & 0 & 0 & 0 & 0 & 0 & 0 & 0 & 0 & 0 & 0 & 0 & 1 & 1 & $0,25 \%$ \\
\hline Pesquisa ação & 0 & 0 & 0 & 0 & 0 & 0 & 0 & 0 & 0 & 0 & 0 & 0 & 0 & 0 & 0 & 0 & 0 & 0 & 0 & 1 & 1 & $0,25 \%$ \\
\hline Quantitativo & 5 & 2 & 1 & 2 & 3 & 1 & $\mathbf{0}$ & 1 & 1 & 1 & 4 & 4 & 9 & 11 & 18 & 18 & 17 & 21 & 21 & 23 & 163 & $41,16 \%$ \\
\hline Estatística descritiva & 5 & 1 & 1 & 2 & 3 & 1 & 0 & 1 & 1 & 1 & 3 & 4 & 6 & 10 & 15 & 14 & 12 & 11 & 15 & 10 & 116 & $29,29 \%$ \\
\hline Análise fatorial & 0 & 1 & 0 & 0 & 0 & 0 & 0 & 0 & 0 & 0 & 0 & 0 & 2 & 0 & 2 & 0 & 1 & 3 & 2 & 4 & 15 & $3,79 \%$ \\
\hline Análise de correlação & 0 & 0 & 0 & 0 & 0 & 0 & 0 & 0 & 0 & 0 & 0 & 0 & 0 & 1 & 0 & 1 & 3 & 2 & 1 & 3 & 11 & $2,78 \%$ \\
\hline Análise de regressão & 0 & 0 & 0 & 0 & 0 & 0 & 0 & 0 & 0 & 0 & 0 & 0 & 0 & 0 & 1 & 2 & 1 & 3 & 0 & 3 & 10 & $2,53 \%$ \\
\hline Equação estrutural & 0 & 0 & 0 & 0 & 0 & 0 & 0 & 0 & 0 & 0 & 1 & 0 & 0 & 0 & 0 & 1 & 0 & 0 & 2 & 2 & 6 & $1,52 \%$ \\
\hline Análise de clusters & 0 & 0 & 0 & 0 & 0 & 0 & 0 & 0 & 0 & 0 & 0 & 0 & 1 & 0 & 0 & 0 & 0 & 2 & 1 & 1 & 5 & $1,26 \%$ \\
\hline Total & 22 & 19 & 10 & 18 & 6 & 9 & 7 & 6 & 12 & 5 & 16 & 18 & 21 & 22 & 37 & 29 & 31 & 35 & 34 & 39 & 396 & $100,00 \%$ \\
\hline
\end{tabular}

Fonte: Dados da pesquisa. 
Nessa evolução das abordagens metodológicas em estudos sobre sustentabilidade ambiental, destaca-se a abordagem qualitativa, 233 (59\%), pelo fato de grande parte dos artigos utilizar o estudo de caso único ou múltiplo. Gallon et al. (2008), Jabbour et al. (2008) e Pato, Sá e Catalão (2009) também encontraram a predominância das abordagens metodológicas qualitativas e de estudo de caso em suas pesquisas sobre sustentabilidade ambiental. Por sua vez, a abordagem quantitativa apresentou um crescimento significativo a partir de 2004 e ultrapassou a abordagem qualitativa entre 2007 a 2011. A predominância da abordagem qualitativa, até 2006, pode ser explicada pelo fato de ser uma área nova do conhecimento, mas com indícios de que está em fase de amadurecimento, predominando estudos quantitativos nos últimos cinco anos.

Observa-se que o método de pesquisa que prevaleceu foi a pesquisa bibliográfica (120 vezes), seguida do estudo de caso (83). É interessante notar que os métodos mais utilizados são as pesquisas qualitativas, predominantes nos 396 artigos investigados, como demonstrado na Tabela 5.

Quanto à abordagem quantitativa, os métodos de análise de dados que predominaram foram: estatística descritiva (116), Análise fatorial (quinze), Análise de correlação (onze) e Análise de regressão (dez), nestes três últimos, destacou-se a análise multivariada.

\section{Características de autoria}

O número de autores em cada artigo evidencia redes e parcerias entre os mesmos. À medida que mais autores publicam em conjunto, isso é indício de que a área é investigada por grupos de pesquisa em detrimento da autoria individual. A colaboração entre autores vem sendo vista internacionalmente como um dos indicadores de qualidade da pesquisa, principalmente em temas interdisciplinares (Subramanyam, 1983), como é o caso da sustentabilidade ambiental.

Como pode ser observado na Figura 3, prevalecem os artigos publicados com dois autores, 157, ou seja, $39,65 \%$. No entanto, quando se analisa o montante das autorias, ou seja, de dois ou mais autores, constata-se que 70,71\% publicam sobre a temática juntos. Gallon et al. (2008) e Rosa e Ensslin (2007) constataram também em suas pesquisas que a maior parte das publicações científicas sobre o tema sustentabilidade foi elaborada por dois autores ou mais autores $(73,21 \%)$. Esse crescimento de redes de colaboração também foi observado na pesquisa de Yarime et al. (2010).

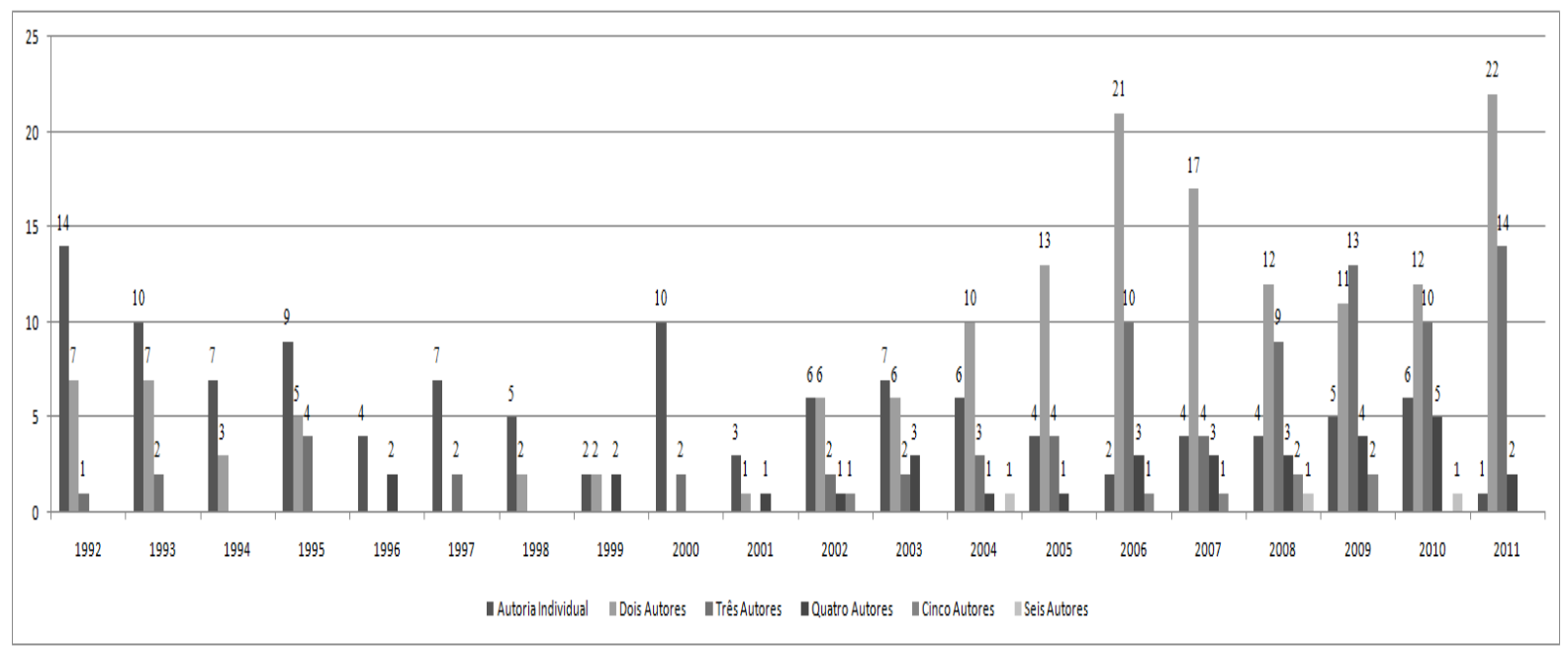

Figura 3. Autoria de Artigos por Ano.

Fonte: Dados da pesquisa.

A Figura 3 esclarece ainda que trabalhos com um único autor predominavam no período de 1992 a 2001. Enquanto as publicações com dois autores começaram a tomar espaço a partir de 1992, os artigos com três e quatro participantes destacaram-se a partir de 1992 e 1996; e os artigos com 5 e 6, não tão comuns, começaram a aparecer a partir de 2002 e 2004, respectivamente. Esses dados 
sugerem a consolidação de grupos de pesquisa sobre sustentabilidade ambiental, o que contribuiu para o fomento do tema. As informações evidenciadas na Figura 3 podem também ser explicadas por meio da Lei de Bradford, em que cada vez mais os pesquisadores comunicam-se e se relacionam entre si, não somente no âmbito nacional, mas também no internacional, desenvolvendo pesquisas em parceria, em outras palavras, é assim que surgem os colégios invisíveis (Balancieri et al., 2005; Vanz \& Stumpf, 2010).

Nesse cenário, remete-se à análise dos autores que mais publicam em determinado assunto revelando assim a emergência da área. A Tabela 6 apresenta os autores mais prolíferos sobre a temática sustentabilidade ambiental no período analisado.

Tabela 6

\section{Autores que Mais Publicam por Ano}

\begin{tabular}{|c|c|c|c|c|c|c|c|c|c|c|c|c|c|c|c|c|c|c|c|c|c|}
\hline Autores/ Ano de Publicação & 92 & 93 & 94 & 95 & 96 & 97 & 98 & 99 & 00 & 01 & 02 & $\mathbf{0 3}$ & 04 & 05 & 06 & 07 & 08 & 09 & 10 & 11 & Total \\
\hline Barbieri, J. C. & & & 1 & 1 & 1 & 1 & 1 & & 1 & & & & 2 & 1 & & & 3 & & 1 & 1 & 14 \\
\hline Jabbour, C. J. C. & & & & & & & & & & & & & & & 2 & 1 & 1 & 3 & 2 & & 9 \\
\hline Ribeiro, M. de S. & & 1 & & & & & 1 & & & & & & 2 & & 2 & 1 & & 2 & & & 9 \\
\hline Abreu, M. C. S. de & & & & & & & & & & & 1 & & 1 & & & & 3 & 2 & 1 & & 8 \\
\hline Santos, F. C. A. & & & & & & & & & & & & & & & 2 & 1 & 1 & 3 & & & 7 \\
\hline Andrade, J. C. S. & & & & & & & & & & & 3 & 2 & & & & & 2 & & & & 7 \\
\hline Campos, L. M. de S. & & & & & & & & & & & 1 & & 1 & & & 1 & 1 & 1 & & 1 & 6 \\
\hline Brito, M. J. de & & & & & & & & & & & & 1 & & & 4 & & & 1 & & & 6 \\
\hline Guimarães, P. C. V. & 1 & 1 & 1 & 1 & & 1 & & & 1 & & & & & & & & & & & & 6 \\
\hline Filho, J. C. L. da S. & & & & & & & & & & & & & & & & & 2 & 2 & 1 & & 5 \\
\hline Amâncio, R. & & & & & & & & & & & & 1 & & & 2 & & 1 & & & 1 & 5 \\
\hline Pedrozo, E. Á. & & & & & & & & & 1 & & & & 1 & & & 1 & 2 & & & & 5 \\
\hline Carrieri, A. de P. & & & & & & 1 & & & & & & 1 & & & & 1 & & 1 & & & 4 \\
\hline Nascimento, L. F. & & & & & & & & 1 & & 1 & & & & 1 & & & & 1 & & & 4 \\
\hline Sellitto, M. A. & & & & & & & & & & & & & & & 1 & 1 & & & 2 & & 4 \\
\hline Batalha, M. O. & & & & & & & & & & & & & & & 1 & & 1 & & & 2 & 4 \\
\hline Cunha, J. C. da & & & & & & & & & & & & & 1 & 2 & & & & & & & 3 \\
\hline Gonçalves-Dias, S. L. F. & & & & & & & & & & & & & & & 2 & & & 1 & & & 3 \\
\hline Jacobi, P. R. & & & & & & & & & 1 & & & & & & & & & & & 2 & 3 \\
\hline Macedo-Soares, T. D. L. V. A. de & & & & & & & & & & & & & & & & 1 & & 1 & & 1 & 3 \\
\hline Motta, S. L. S. & & & & & & & & & & 1 & & 1 & & & & & & & & 1 & 3 \\
\hline Oliveira, J. A. P. de & & & & & & & & & & & 1 & & 1 & 1 & & & & & & & 3 \\
\hline Silva, T. N. da & & & & & & & & & 1 & & & & 1 & & & & 1 & & & & 3 \\
\hline Figueiredo, M. A. G. de & & & & & 1 & & 1 & & & & & & & & & & & & 1 & & 3 \\
\hline Oliveira, O. J. de & & & & & & & & & & & & & & & & & & & 3 & & 3 \\
\hline Selig, P. M. & & & & & & & & & & & 1 & & & & & & & 1 & & 1 & 3 \\
\hline Oliveira, B. C. de & & & & & & & & & & & & & & & 1 & & 2 & & & & 3 \\
\hline Claro, D. P. & & & & & & & & & & & 1 & & 1 & & & & 1 & & & & 3 \\
\hline
\end{tabular}




\section{Tabela 6 (continuação)}

\begin{tabular}{|c|c|c|c|c|c|c|c|c|c|c|c|c|c|c|c|c|c|c|c|c|c|}
\hline Autores/Ano de Publicação & 92 & 93 & 94 & 95 & 96 & 97 & 98 & 99 & $\mathbf{0 0}$ & 01 & 02 & 03 & 04 & 05 & 06 & 07 & 08 & 09 & 10 & 11 & Total \\
\hline Siena, O. & & & & & & & & & & & & & & & & & 1 & & 1 & 1 & 3 \\
\hline Nossa, V. & & & & & & & & & & & & & & & & & & 1 & 1 & 1 & 3 \\
\hline Demajorovic, J. & & & & 2 & & 1 & & & & & & & & & & & & & & & 3 \\
\hline Spers, E. E. & & & & & & & & & & & & & & & 1 & & 1 & & & 1 & 3 \\
\hline Claro, P. B. de O. & & & & & & & & & & & 1 & & 1 & & & & 1 & & & & 3 \\
\hline Teodósio, A. dos S. de S. & & & & & & & & & & & & & & & 1 & & & 1 & & 1 & 3 \\
\hline Total & 1 & 2 & 2 & 4 & 2 & 4 & 3 & 1 & 5 & 2 & 9 & 6 & 12 & 5 & 19 & 8 & 24 & 21 & 13 & 14 & 157 \\
\hline
\end{tabular}

Fonte: Dados da pesquisa.

A Tabela 6 elenca que 31 pesquisadores, ou seja, 91\% começaram a publicar a partir da última década, e esse fato indica que o tema sustentabilidade ambiental é novo e emergente no campo da área de Administração, no Brasil. Áreas emergentes tendem a ter poucos pesquisadores com histórico de pesquisa relevante (Nederhof, 2006). Entre os 396 artigos investigados, somente 34 autores publicaram de três a quatorze artigos, ou seja, 4\% do montante de 853 autores. Sendo assim, os resultados são corroborados, em parte, pela Lei de Lotka, pois, neste trabalho, foi encontrada uma porcentagem superior ao padrão estabelecido por Lotka (1926), que também enfatiza que poucos pesquisadores publicam muito; e muitos pesquisadores publicam pouco, referindo, assim, a relevância desses poucos autores para a área investigada.

\section{Referências bibliográficas utilizadas nos artigos}

A análise das referências pode ser vista como fator preponderante para continuidade das pesquisas, pois aponta quais autores são mais citados em determinado tema, dessa maneira, contribuindo e proporcionando um norte para pesquisadores experientes e, principalmente, para os iniciantes, influenciando, de maneira direta, o crescimento de futuras pesquisas sobre o tema e corroborando a posteriori na disseminação e fomento do assunto investigado. A Figura 4 mostra a frequência dos autores e organismos mais citados sobre sustentabilidade ambiental nos periódicos investigados.

Internacionalmente, há programas, como o Journal Citation Reports, que fazem esse tipo de trabalho para os pesquisadores. No Brasil, na ausência de mecanismos do gênero, estudos de análise das referências vêm sendo executados a despeito da grande dificuldade operacional sem softwares específicos (Bignetti \& Paiva, 2002).

Ao analisar a Figura 4, nota-se que há destaque para algumas citações internacionais, tais como Porter, 86; Sachs, 52; Linde, 40; Elkington, 24, o que corrobora as pesquisas de Jabbour et al. (2008), que se justifica pelo fato do número restrito de artigos publicados nas principais revistas nacionais em administração. Outras pesquisas realizadas também mostram que os pesquisadores brasileiros privilegiam periódicos internacionais nas referências, como os estudos de Graeml e Macadar (2010) e Francisco (2011).

Para Goulart e Carvalho (2008), os periódicos internacionais são mais valorizados pela amplitude de circulação do conhecimento produzido e prestígio que têm entre os pesquisadores, em razão de, majoritariamente, serem publicados em língua inglesa. 


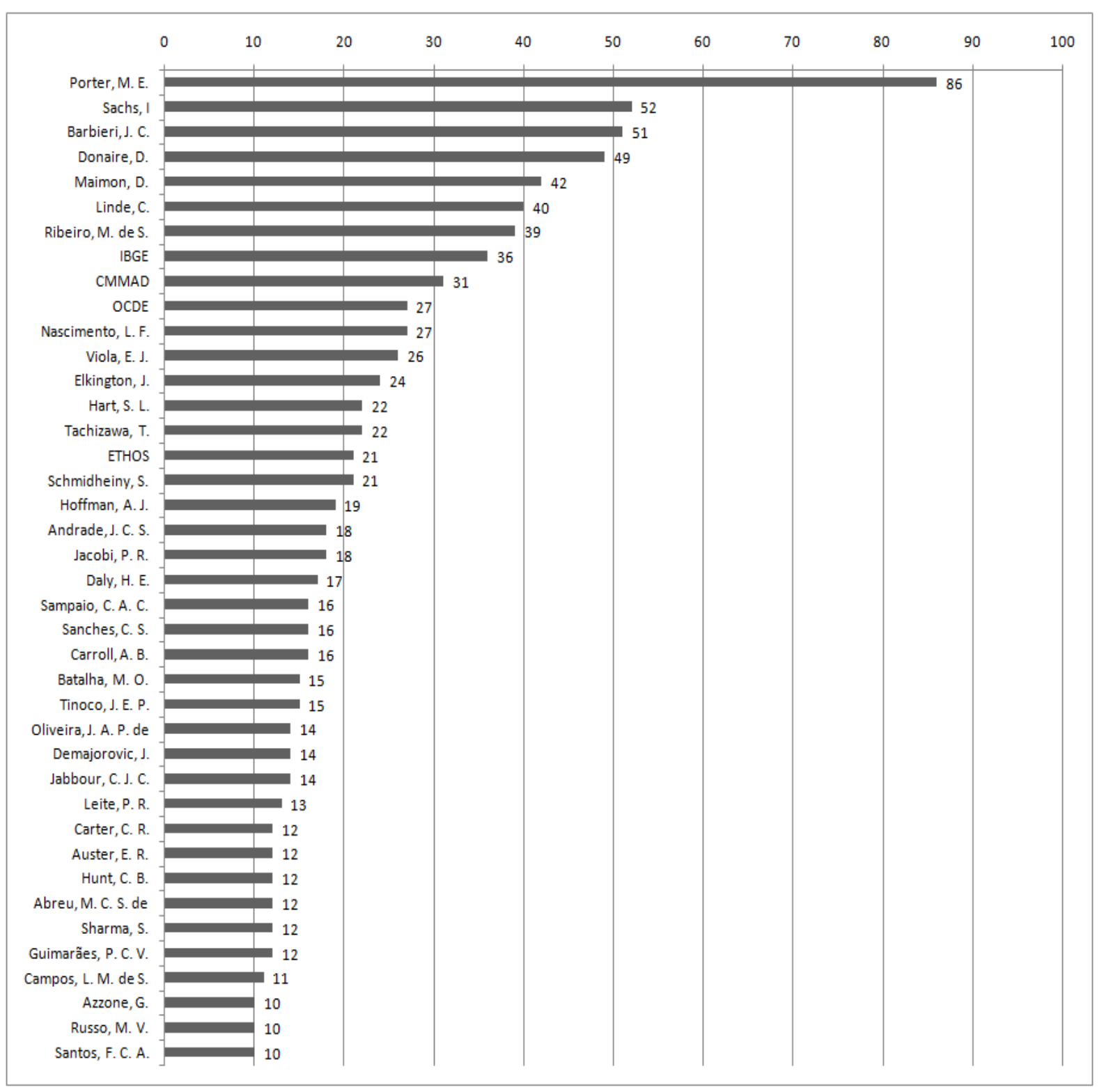

Figura 4. Autores e Organismos Mais Citados. Fonte: Dados da pesquisa.

O Instituto Brasileiro de Geografia e Estatística (IBGE), a CMMAD e a Organization for Economic Cooperation and Development (OCDE) são os organismos mais citados nas referências dos artigos pesquisados, totalizando 36, 31 e 27 vezes, respectivamente. O IBGE tem relação direta com a temática sustentabilidade ambiental pelas importantes pesquisas censitárias publicadas periodicamente pela instituição. Enquanto a CMMAD é uma referência muito utilizada na maioria dos artigos sobre sustentabilidade e meio ambiente pelo relatório Nosso Futuro Comum, particularmente, o conceito de desenvolvimento sustentável, que é o mais difundido e citado em artigos científicos da área, é extraído dessa obra. Algumas pesquisas referem o aumento de artigos a partir da publicação dessa obra (Schubert \& Láng, 2005). Já a OCDE se destaca por publicar diversos relatórios na área ambiental.

É importante mencionar que os autores Barbieri, Ribeiro, Nascimento, Andrade, Jacobi, Batalha, Oliveira, Demajorovic, Jabbour, Abreu, Guimarães, Campos e Santos, além de serem os que mais publicam sobre o tema sustentabilidade ambiental, são, também, aqueles mais citados nas referências dos artigos investigados, indicando uma forte tendência de crescimento na participação dos autores nacionais nas citações sobre o tema em questão, como mostra a Figura 5. 


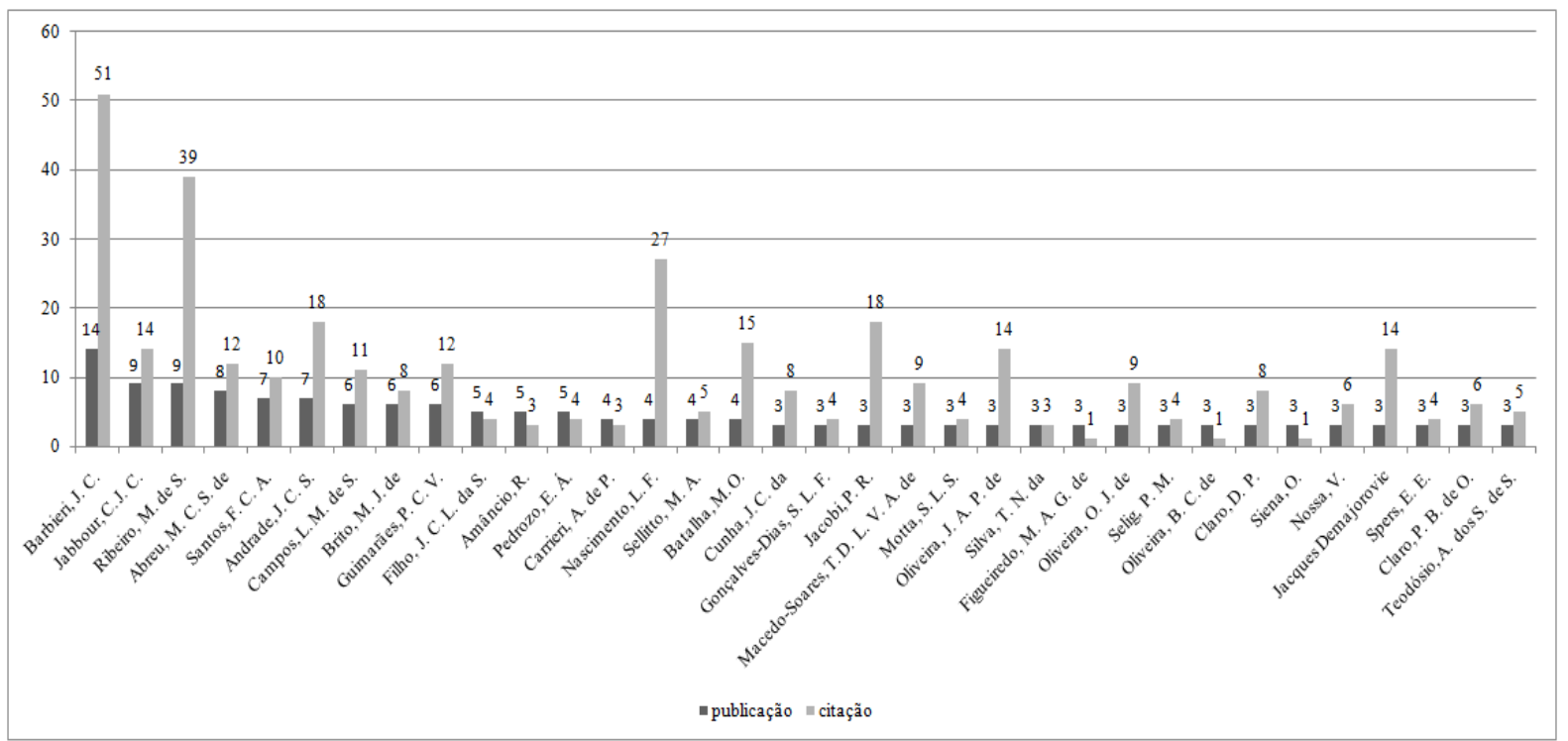

Figura 5. Autores Mais Prolíferos e Suas Citações.

Fonte: Dados da pesquisa.

Essa forte concentração de publicações em um número muito pequeno de autores vai ao encontro da Lei de Lotka (A. R. Nascimento, Santos, Salotti, \& Múrcia, 2009; Moretti \& Campanário, 2009) e fortifica os resultados de outros estudos bibliométricos atinentes à sustentabilidade ambiental que constataram a concentração da produção da área em um número restrito de pesquisadores (Chabowski, Mena, \& Gonzalez-Padron, 2011; Grzebieluckas, Campos, \& Selig, 2012; Jabbour, Santos, \& Barbieri, 2008; Machado, Nascimento, \& Múrcia, 2009; Schubert \& Láng, 2005). O tema está em evidência na maioria dos periódicos estudados, com tendência de crescimento nos últimos anos, como aponta também o estudo Chabowski et al. (2011) na área de marketing.

Diante do exposto, salienta-se a Lei de Lotka (1926), que versa sobre a produtividade dos autores de um determinado campo científico, ou seja, a geração de novos conhecimentos é inerente ao desenvolvimento e crescimento da literatura produzida (Urbizagastegui, 2009). Conclui-se com isso que uma pesquisa só está terminada quando ela é referenciada (A. R. Nascimento et al., 2009; Moretti \& Campanário, 2009).

\section{Considerações Finais}

Neste estudo, investigou-se o perfil das pesquisas e a evolução do tema sustentabilidade ambiental nos artigos publicados em revistas Qualis de Administração de A1 a B2, no período de 1992 a 2011. Os resultados da pesquisa mostraram que o tema ora investigado começou a se destacar de 1992 a 1995, tendo uma queda nos anos subsequentes, porém, a partir de 2002, o tema começou a crescer novamente, principalmente a partir do ano de 2005, podendo ser indício da consolidação e o amadurecimento da área a partir desse período. A maior parte dos artigos publicados está concentrada em cinco revistas: Administração Pública (RAP), Revista Eletrônica de Administração (REAd), Revista de Administração de Empresas (RAE), Gestão \& Produção (G\&P) e Produção.

Os temas que se destacaram, em ordem decrescente, dos 396 artigos investigados, foram: gestão ambiental, desenvolvimento sustentável, gestão de resíduos, recursos hídricos, contabilidade ambiental, marketing verde, sistema de gestão ambiental, responsabilidade social ambiental, inovação ambiental, sustentabilidade empresarial, mecanismo de desenvolvimento limpo e agricultura e meio ambiente. Alguns temas passaram a ser investigados mais recentemente, como responsabilidade socioambiental, sustentabilidade empresarial e, principalmente, mecanismo e desenvolvimento limpo, 
que começou a ser evidenciado a partir de 2007, logo após a ratificação do Protocolo de Quioto. Verificou-se também um crescimento de novos temas a partir de 2005, entre eles: gestão de resíduos, marketing verde, sistema de gestão ambiental, responsabilidade socioambiental, inovação ambiental, sustentabilidade empresarial, Mecanismo de Desenvolvimento Limpo, cadeia de suprimento verde, produção mais limpa, entre outros.

Constatou-se que a maioria dos artigos investigados adota o enfoque qualitativo, mas os dados assinalam uma tendência de crescimento da abordagem quantitativa, que ultrapassou a qualitativa a partir de 2007.

Nos artigos pesquisados, prevalecem publicações com dois ou mais autores, o que indica a existência de grupos de pesquisa consolidados sobre sustentabilidade ambiental. Por um lado, há poucos autores com histórico de pesquisa relevante, ou seja, que publicam nos periódicos nacionais considerados os mais qualificados da área de administração pela CAPES. Por outro lado, há muitos pesquisadores que publicam pouco nestas revistas. A análise das referências mostrou que se destacam algumas citações internacionais, pelo fato de haver um número restrito de artigos publicados em revistas nacionais, em administração, até a década de 1990. Da mesma maneira, há autores nacionais que se sobressaem entre os que mais publicam e também são os mais citados nas referências dos artigos investigados.

Em suma, os resultados apontam que a área é recente e que ainda não atingiu maturidade nas publicações, mas que está a caminho da consolidação, pois o número de artigos mostra tendência de crescimento e há algumas características que favorecem a qualidade da pesquisa em sustentabilidade ambiental, a saber: a pluralidade de áreas de interesse; o crescimento de estudos feitos por grupos de pesquisadores ao invés de iniciativas individuais; a distribuição que tende a ser uniforme entre artigos quantitativos e qualitativos nos últimos anos do estudo, apresentando uma cobertura metodológica complementar que pode trazer maior qualidade às pesquisas; a tendência de crescimento entre os pesquisadores da área e a consolidação de referências de autores nacionais de destaque.

Como limitação do estudo, cabe ressaltar que a amostra restringiu-se às publicações das revistas A1 a B2 Qualis da Área de Administração, no triênio 2007-2009. Assim, ampliar essa faixa de análise para os estratos A1 a B5 poderia trazer novas informações pertinentes a esse vasto universo dos periódicos acadêmicos. Algumas revistas de áreas correlatas, como de Economia e Turismo, não participaram da amostra, o que poderia contribuir para trazer novas percepções relativamente à sustentabilidade ambiental, principalmente porque foram identificados artigos sobre essas áreas nos periódicos analisados.

Sugere-se, para futuros estudos, análise dos conteúdos utilizados na fundamentação teórica, o aprofundamento das abordagens metodológicas e do estudo de redes sociais para identificar as redes formadas por pesquisadores e IES.

\section{Referências}

Balancieri, R., Bovo, A. B., Kern, V. M., Pacheco, R. C. S. dos, \& Barcia, R. M. (2005). A análise de redes de colaboração científica sob as novas tecnologias de informação e comunicação: um estudo na plataforma lattes. Ciência da Informação, 34(1), 64-77. doi: 10.1590/S010019652005000100008

Balestrin, A., Verschoore, J. R., \& Reyes, E., Jr. (2010). O campo de estudo sobre redes de cooperação interorganizacional no Brasil. Revista de Administração Contemporânea, 14(3), 458-477. Recuperado de http://www.scielo.br/pdf/rac/v14n3/v14n3a05.pdf. doi: 10.1590/S141565552010000300005 
Barbieri, J. C. (2001). Desenvolvimento e meio ambiente: as estratégias de mudanças da Agenda 21. Petrópolis: Vozes.

Bardin, L. (2009) Análise de conteúdo (5a ed.). Lisboa: Edições 70.

Bertero, C. O., Caldas, M. P., \& Wood, T., Jr. (1999). Produção científica em administração de empresas: provocações, insinuações e contribuições para um debate local. Revista de Administração Contemporânea, 3(1), 147-178. doi: 10.1590/S1415-65551999000100009

Bignetti, L. P., \& Paiva, E. L. (2002). Ora (direis) ouvir estrelas!: estudo das citações de autores de estratégia na produção acadêmica brasileira. Revista de Administração Contemporânea, 6(1), 105-125. doi: 10.1590/S1415-65552002000100007

Borges, P. C. R. (2002). Métodos quantitativos de apoio à bibliometria: a pesquisa operacional pode ser uma alternativa? Ciência da Informação, 31(3), 5-17.

Bufrem, L., \& Prates, Y. (2005). O saber científico registrado e as práticas de mensuração da informação. Ciência da Informação, 34(2), 9-25. doi: 10.1590/S0100-19652005000200002

Chabowski, B. R., Mena, J. A., \& Gonzalez-Padron, T. L. (2011). The structure of sustainability research in marketing, 1958-2008: a basis for future research opportunities. Academy of Marketing Science, 39(1), 55-70. doi: 10.1007/s11747-010-0212-7

Comissão Mundial sobre Meio Ambiente e Desenvolvimento. (1988). Nosso futuro comum. Rio de Janeiro: Fundação Getúlio Vargas.

Conferência das Nações Unidas sobre Meio Ambiente e Desenvolvimento. (1996). Agência 21. Brasília: Senado Federal.

Cooper, H. M., \& Lindsay, J. J. (1998). Research synthesis and meta-analysis. In L. Bickman \& D. J. Rog (Eds.), Handbook of applied social research methods (pp. 315-342). Thousand Oaks, CA: Sage Publications.

Coordenação de Aperfeiçoamento de Pessoal de Nível Superior. (2011). Revistas Qualis. Recuperado de http://www.capes.gov.br/avaliacao/qualis

Donaire, D. (1994). Considerações sobre a influência da variável ambiental na empresa. Revista de Administração de Empresas, 34(2), 68-77.

Francisco, E. de R. (2011). RAE-eletrônica: exploração do acervo à luz da bibliometria, geoanálise e redes sociais. Revista de Administração de Empresas, 51(3), 280-306. doi: 10.1590/S003475902011000300008

Gallon, A. V., Rover, S., Souza, F. C. de, \& Bellen, H. M. van. (2008). Um estudo longitudinal da produção científica em administração direcionada à temática ambiental. Revista Alcance, 15(1), 81-101.

Goulart, S., \& Carvalho, C. A. (2008). O caráter da internacionalização da produção científica e sua acessibilidade restrita. Revista de Administração Contemporânea, 12(3), 835-853. doi: $10.1590 / \mathrm{S} 1415-65552008000300011$

Graeml, A. R., \& Macadar, M. A. (2010). Análise de citações utilizadas em ADI: 10 anos de anais digitais do Enanpad (1997-2006). Revista de Administração Contemporânea, 14(1), 122-148. Recuperado de http://www.scielo.br/pdf/rac/v14n1/08.pdf. doi: 10.1590/S141565552010000100008 
Grzebieluckas, C., Campos, L. M. S. de, \& Selig, P. M. (2012). Contabilidade e custos ambientais: um levantamento da produção científica no período de 1996 a 2007. Produção, 22(2), 322-332. doi: doi.org/10.1590/S0103-65132011005000054

Guarido Filho, E. R., Machado-da-Silva, C. L., \& Gonçalves, S. A. (2010). Organizational institutionalism in the academic field in Brazil: social dynamics and networks [Edição Especial]. Revista de Administração Contemporânea, 14, 149-172. Recuperado de http://www.scielo.br/pdf/rac/v14nspe/a07v14ns.pdf. doi: 10.1590/S1415-65552010000600007

Jabbour, C. J. C., Santos, F. C. A., \& Barbieri, J. C. (2008). Gestão ambiental empresarial: um levantamento da produção científica brasileira divulgada em periódicos da área de administração entre 1996 e 2005. Revista de Administração Contemporânea, 12(3), 689-715. doi: $10.1590 / \mathrm{S} 1415-65552008000300005$

Laruccia, M. M. (2012). Sustainability strategies: when does it pay to be green? Resenha Bibliográfica. Revista de Administração Contemporânea, 16(1), 172-174. Recuperado de http://www.scielo.br/pdf/rac/v16n1/a11v16n1.pdf. doi: 10.1590/S1415-65552012000100011

Leite, G. A., Filho (2008). Padrões de produtividade de autores em periódicos e congressos na área de contabilidade no Brasil: um estudo bibliométrico. Revista de Administração Contemporânea, 12(2), 533-554. doi: 10.1590/S1415-65552008000200011

Leonidou, C. N., \& Leonidou, L. C. (2011). Research into environmental marketing/management: a bibliographic analysis. European Journal of Marketing, 45(1/2), 68-103. doi: $10.1108 / 03090561111095603$

Lotka, A. J. (1926). The frequency distribution of scientific productivity. Journal of the Washington Academy of Sciences, 16(12), 317-323.

Lyra, M. G., Gomes, R. C., \& Jacovine, L. A. G. (2009). O papel dos stakeholders na sustentabilidade da empresa: contribuições para construção de um modelo de análise [Edição Especial]. Revista de Administração Contemporânea, 13, 39-52. Recuperado em http://www.scielo.br/pdf/rac/v13nspe/a04v13nspe.pdf. doi: 10.1590/S141565552009000500004

Machado-da-Silva, C. L., Guarido Filho, E. R., Rossoni, L., \& Graeff, J. F. (2008). Periódicos brasileiros de administração: análise bibliométrica de impacto no triênio 2005-2007. RACEletrônica, 2(3), 351-373. Recuperado de http://www.anpad.org.br/periodicos/arq_pdf/a_821.pdf

Machado, M. R., Nascimento, A. R., \& Múrcia, F. D-R. (2009, julho). Análise critica - epistemológica da produção científica em contabilidade social e ambiental no Brasil. Anais do Congresso USP Controladoria e Contabilidade, São Paulo, SP, Brasil, 9.

Maimon, D. (1992). Empresa e meio ambiente. Tempo e Presença, 14(261), 49-51.

Maimon, D. (1994). Eco-estratégia nas empresas brasileiras: realidade ou discurso? Revista de Administração de Empresas, 34(4), 119-130.

Maimon, D. (1996). Passaporte verde: gestão ambiental e competitividade. Rio de Janeiro: Qualitymark.

Melo, P. L. de R., \& Andreassi, T. (2010). Publicação científica nacional e internacional sobre franchising: levantamento e análise do período 1998-2007. Revista de Administração Contemporânea, 14(2), 268-288. Recuperado de http://www.scielo.br/pdf/rac/v14n2/v14n2a06.pdf. doi: 10.1590/S1415-65552010000200006 
Moretti, S. L. A., \& Campanário, M. de A. (2009). A produção intelectual brasileira em responsabilidade social empresarial - RSE sob a ótica da bibliometria [Edição Especial]. Revista de Administração Contemporânea, 13, 68-86. Recuperado de http://www.scielo.br/pdf/rac/v13nspe/a06v13nspe.pdf. doi: 10.1590/S141565552009000500006

Nascimento, A. R. do, Junqueira, E., \& Martins, G. de A. (2010). Pesquisa acadêmica em contabilidade gerencial no Brasil: análise e reflexões sobre teorias, metodologias e paradigmas. Revista de Administração Contemporânea, 14(6), 1113-1133. Recuperado de http://www.scielo.br/pdf/rac/v14n6/v14n6a08.pdf. doi: 10.1590/S1415-65552010000700008

Nascimento, A. R. do, Santos, A. dos, Salotti, B., \& Múrcia, F. D-R. (2009). Disclosure social e ambiental: análise das pesquisas científicas veiculadas em periódicos de língua inglesa. Revista Contabilidade Vista \& Revista, 20(1), 15-40.

Nascimento, S. do, \& Beuren, I. M. (2011). Redes sociais na produção científica dos programas de pós-graduação de ciências contábeis do Brasil. Revista de Administração Contemporânea, 15(1), 47-66. Recuperado de http://www.scielo.br/pdf/rac/v15n1/v15n1a04.pdf. doi: $10.1590 /$ S1415-65552011000100004

Nederhof, A. J. (2006). Bibliometric monitoring of research performance in the social sciences and the humanities: a review. Scientometrics, 66(1), 81-100. doi: 10.1007/s11192-006-0007-2

Pato, C., Sá, L. M., \& Catalão, V. L. (2009). Mapeamento de tendências na produção acadêmica sobre educação ambiental. Educação em Revista, 25(2), 213-233. doi: 10.1590/S010246982009000300011

Pereira, G. M. de C., Yen-Tsang, C., Manzini, R. B., \& Almeida, N. V. (2011). Sustentabilidade socioambiental: um estudo bibliométrico da evolução do conceito na área de gestão de operações. Produção, 21(4), 610-619. doi: 10.1590/S0103-65132011005000053

Pritchard, C. (1998). Trends in economic evaluation [OHE Briefing $\mathrm{n}^{\mathbf{0}}$ 36], Office of Health Economics, London, UK. Recuperado de http://ohematerials.org/publication_pdfs/1998_Trends_in_Economic_Eval_Pritchard_.pdf

Rosa, F. S. da, \& Ensslin, S. R. (2007, novembro). Tema “a gestão ambiental” em eventos científicos: um estudo exploratório nos eventos avaliados segundo critério Qualis da Capes. Anais do Encontro Nacional de Gestão Empresarial e Meio Ambiente, Curitiba, PR, Brasil, 9.

Sachs, I. (1986). Ecodesenvolvimento: crescer sem destruir. São Paulo: Vértice.

Sachs, I. (1993). Estratégias de transição para o século XXI: desenvolvimento e meio ambiente. São Paulo: Studio Nobel/Fundap.

Sampaio, C. H., \& Perin, M. G. (2006). Pesquisa científica da área de marketing: uma revisão histórica (Documentos e Debates). Revista de Administração Contemporânea, 10(2), 179-202. doi: 10.1590/S1415-65552006000200010

Schubert, A., \& Láng, I. (2005). The literature after math of the brundtland report 'ur common future'. A scientometric study based on citations in science and social science journals. Environment, Development and Sustainability, 7(1), 1-8. doi: 10.1007/s10668-003-0177-5

Sgarbi, V. S., Lima, M. T. A. de, Santos, C. de F. S. O., \& Falcão, M. C. (2008, novembro). Os jargões da sustentabilidade: uma discussão a partir da produção científica nacional. Anais do Encontro Nacional de Gestão Empresarial e Meio Ambiente, Porto Alegre, RS, Brasil, 10.

Singleton, R. A., \& Straits, B. C. (1999). Approaches to social research. New York: Oxford University Press. 
Souza, M. T. S. de, Machado Júnior, C., Parisotto, I. R. dos S., \& Silva, H. E. M. da. (2011, setembro). A pós-graduação stricto sensu em administração como elemento de formação de pesquisadores na área ambiental. Anais do Encontro Nacional da Associação Nacional de Pós-Graduação e Pesquisa em Administração, Rio de Janeiro, RJ, Brasil, 35.

Subramanyam, K. (1983). Bibliometric studies of research collaboration: a review. Journal of Information Science, 6(1), 33-38. doi: 10.1177/016555158300600105

Teixeira, M. G. C., \& Bessa, E. da S. (2009). Estratégias para compatibilizar desenvolvimento econômico e gestão ambiental numa atividade produtiva local [Edição Especial]. Revista de Administração Contemporânea, 13, 1-18. Recuperado de http://www.scielo.br/pdf/rac/v13nspe/a02v13nspe.pdf. $\quad$ doi: 10.1590/S141565552009000500002

Testa, J. (1998). A base de dados ISI e seu processo de seleção de revistas. Ciência da Informação, 27(2), 233-235. doi: 10.1590/S0100-19651998000200022

Uehara, T. H. K., Otero, G. G. P., Martins, E. G. A., Philippi, A., Jr., \& Mantovani, W. (2010). Pesquisas em gestão ambiental: análise de sua evolução na Universidade de São Paulo. Ambiente \& Sociedade, 13(1), 165-185.

Urbizagastegui, R. (2009). Crescimento da literatura e dos autores sobre a Lei de Lotka. Ciência da Informação, 38(3), 111-129. doi: 10.1590/S0100-19652009000300008

Vanti, N. A. P. (2002). Da bibliometria à webometria: uma exploração conceitual dos mecanismos utilizados para medir o registro da informação e a difusão do conhecimento. Ciência da Informação, 31(2), 152-162. doi: 10.1590/S0100-19652002000200016

Vanz, S. A. S. de, \& Stumpf, I. R. C. (2010). Colaboração científica: revisão teórico-conceitual. Perspectivas em Ciência da Informação, 15(2), 42-55. doi: 10.1590/S141399362010000200004

Wezel, A., \& Soldat, V. (2009). A quantitative and qualitative historical analysis of the scientific discipline of agroecology. International Journal of Agricultural Sustainability, 7(1), 3-18. doi: 10.3763/ijas.2009.0400

Yarime, M., Takeda, Y., \& Kajikawa, Y. (2010). Towards institutional analysis of sustainability science: a quantitative examination of the patterns of research collaboration. Sustainability Science, 5(1), 115-125. doi: 10.1007/s11625-009-0090-4 